PÉREZ GONZÁLEZ, S., «El Derecho ante las derivas laborales de la nueva economía», REDUR 8, diciembre 20 Io, págs.

I23-I45. ISSN i695-078X

\title{
EL DERECHO ANTE LAS DERIVAS LABORALES DE LA NUEVA ECONOMÍA
}

\author{
Sergio PÉREZ GONZÁLEZ \\ INVESTIGADOR DEL ÁREA DE FILOSOFÍA DEL DERECHO* \\ UNIVERSIDAD DE LA RIOJA
}

SUMARIO: I. Ciclo de producción fordista. II. Derecho regulativo fordista. III. Crisis del fordismo y giro lingüístico de la economía. IV. Crisis del objeto regulado: crisis del concepto trabajo. V. Derecho del trabajo postregulativo. VI. Constitución del derecho laboral postregulativo: la función performativa. VII. Conclusiones. VIII. Bibliografía citada.

RESUMEN: El derecho ha sido siempre una estructura movediza, una disposición de previsiones temblorosa que, en las últimas décadas, ha debido enfrentarse a seísmos especialmente virulentos; Y es que la nueva economía y sus derivas laborales requieren colosales esfuerzos de adaptación, así como renovados equilibrismos jurídicos capaces de seguir manteniendo paces sociales y progresos sostenidos. Para analizar esta renovación del escenario en el que actúa el derecho ${ }^{1}$, proponemos un itinerario concreto; Un itinerario vinculado a las relaciones laborales como campo especialmente dinámico: Desde un análisis del ciclo de producción fordista (I), basado en la fábrica y en la producción en cadena, constatamos el desarrollo paralelo de un derecho del trabajo regulativo (II) que, en cierto modo, entra en crisis cuando el ciclo de producción (III) y el mismo concepto de trabajo (IV) lo hacen. Es en ese punto en el que sugerimos la emergencia de un derecho laboral evolucionado (V y VI) que, tal vez, pueda dar la pauta para comprender qué nuevos modos se muestran más aptos en la producción de derecho, así como los efectos que conllevan, casi como conclusión especulativa (VII).

PALABRAS CLAVES: Filosofía del Derecho; Derecho del trabajo; postfordismo; Derecho regulativo; función performativa.

KEYWORDS: Philosophy of Law; Labour Law; postfordism; regulatory Law; performative function.

\footnotetext{
* Los aciertos que pudiera haber en este artículo se han gestado en el Área de Filosofía del Derecho de la Universidad de La Rioja, donde realizo la tesis doctoral bajo la dirección de los profesores Raúl Susín y José M. Martínez de Pisón, así como en los esclarecedores debates filosóficos tenidos en la Sala de Máquinas con Belén Castellanos y David San Martín; También quisiera agradecer sus observaciones a Daniel Oliver.

${ }^{\mathrm{I}}$ No resulta vano advertir un marco enunciativo básico en el que comprender el derecho que ha servido de referencia para este estudio: Aquél relativo a las prácticas y discursos que emanan del estamento que el propio derecho refiere como jurídico. Circunscribimos estas notas, por tanto, al derecho formalmente refrendado por alguna de las manifestaciones del Estado, a la producción de legalidad, a la interpretación jurisprudencial e, incluso, a la comunicación que queda enclaustrada en estos ámbitos procesales. Obviamos, por tanto, derechos o códigos que operan efectivamente en determinados contextos, grupos, instituciones o entidades privadas que, en todo caso, quedan al margen de ese marco formal habilitado, en último término, por cierta interpretación política que hace de la ciudadanía categoría de legitimación (refiriéndonos así a un sistema democrático básico). Del mismo modo debemos apuntar que seguimos cierto itinerario desde lo concreto, desde las prácticas y experiencias laborales que limitan el alcance del artículo al derecho laboral o, en todo caso, al derecho que, de un modo $u$ otro, pretendió construirse en torno al concepto trabajo tal y como fue definido por la economía política.
} 
Por consiguiente, Hermógenes, no es cosa de cualquier hombre el imponer nombres, sino de un «nominador». Y éste es, según parece, el legislador, el cual, desde luego, es entre los hombres el más escaso de los artesanos.

Platón, por boca de Sócrates, en el Cratilo (389a)

\section{Ciclo de producción fordista}

Advertía Bataille -a propósito de la noción del gasto ${ }^{2}$ que la racionalidad económica es un movimiento interno, subyugado, inserto en la esencia irracional de la gestión humana de la riqueza. Cuando el siglo XX era clausurado por las crisis financieras que resquebrajaban cualquier posibilidad de ratio colectiva global, la lectura de Bataille parecía tomar un sentido pleno, como si el mundo se moviera en torno a inescrutables pasiones empresariales y financieras ${ }^{3}$.

Sin embargo, más allá de rastrear esencias estructurales, lo cierto es que esa racionalidad, ocasional o no, pudo constatarse fenoménicamente durante los años gloriosos del fordismo, tiempos de consideración común por lo útil y lo necesario, elevados a doctrina económica por el keynesianismo y a teleología jurídico-política por el Estado del bienestar. Las rutinas sindicales, las grietas en el continuum, las irritaciones y los desasosiegos parecían contenerse en un marco de racionalidad que los envolvía, como revueltas intestinas en un cuerpo sano o, al menos, sanable.

Encajados en aquel marco racional ${ }^{4}$, el equilibrio económico asentado sobre la producción de mercancías -elaboradas por un ejército estable de trabajadores-, la acumulación en stocks y la predicción de un consumo masivo y constante, proporcionaba cierta seguridad. La previsión del futuro económico se proyectaba a partir de esas repeticiones periódicas producción/consumo, cuya circularidad era interrumpida, si acaso, por crisis de superproducción, desajustes interpretables como excepción -suspiro ocasional del sistema, hendidura revestible- o como síntoma de normas sobrevenidas -anuncio de desenlaces que remitirían a nuevas circularidades. El ciclo económico, por tanto, era vivido como un movimiento pendular eterno, afectado ocasionalmente por aquellas arritmias referidas, generadoras de literaturas contradictorias 5 .

2 BATAILLE, G., La parte maldita, precedida de la noción del gasto, trad. Francisco Muñoz de Escalona, Barcelona, Icaria, I987, págs. 25 ss.

${ }^{3}$ Las primeras crisis del petróleo y la inhabilitación del patrón oro parecen marcar esa finitud del equilibrio del ciclo productivo, desterrando la economía a la estantería de las literaturas no científicas. Las previsiones de rumbo, zarandeadas ahora por las crisis globales, parecen trocarse derivas, derroteros inciertos. Ya no hay proyecciones válidas y, si acaso, el negocio radica en las proyecciones sobre proyecciones (análisis bursátil).

${ }^{4}$ Marco de racionalidad construido sobre la metamorfosis del trabajo (GORZ, A., Metamorfosis del trabajo, trad. M. Carmen Ruiz, Madrid, Sistema, I995) surgida de otro marco de racionalidad (o «pluralidad de racionalidades») capitalista pre-industrial: «Esta forma de organización capitalista, arraigada en la tradición, tenía una racionalidad propia incuestionable. Tradicional era el modo de vida, tradicionales las tasas de beneficio, la cantidad de trabajo proporcionado, el modo de gestión de la empresa y las relaciones entre empresarios y obreros. Todo esto dominaba la forma en la que se llevaban los negocios y subyacía al 'espíritu', a la ética, de este tipo de empresario preindustrial» (MARAZZI, C., El sitio de los calcetines: El giro lingüístico de la economía Y sus efectos sobre la política, trad. Marta Malo de Molina Bodelón, Madrid, Akal, 2003, págs. 20-21).

${ }^{5}$ Se trata, si acaso, de las literaturas contradictorias que Lyotard sintetiza en «funcionalismo o criticismo del saber». Se trata de alternativas inscritas en un mismo marco de racionalidad que sólo podría superarse mediante una distinción de diferente grado: «Uno está tentado a escapar a esa alternativa distinguiendo dos tipos de saber, uno positivista (...) otro crítico o reflexivo o hermenéutico que, al interrogarse directamente o indirectamente sobre los valores o los objetivos, obstaculiza toda 'recuperación'» (LYOTARD, J.F., La condición postmoderna, trad. Mariano Antolín, Buenos Aires, Cátedra, I99I, pág. I4); Es decir, una alternativa que no opte necesariamente por procesos racionales únicos, contiguos, solapados o enfrentados. 
Los procesos productivos -que operaban en su circuito de racionalidadimplementaban, ajenos a la posibilidad de crisis fatales, técnicas tendentes al abaratamiento de los costes implicados. Se ampliaba en esta rutina el horizonte de consumidores sobre la base de un ejército cada vez mayor de trabajadores industriales. El consumo de masas y la producción fabril suponían, así, los pistones que inyectaban dinamismo al ciclo productivo. Es en esta circulación en la que pudo confirmarse un concepto de trabajo diferenciado sincrónica y diacrónicamente del resto de actividades humanas:

(I) Diacrónicamente porque la diferenciación del trabajo estaba estrictamente marcada por el paso bajo el umbral de la entrada a la fábrica, marcada por el movimiento mediante el que el trabajador lo penetraba y, por tanto, marcada por el tiempo.

(2) Sincrónicamente porque la conformación de las disciplinas modernas instituyó el concepto preciso de trabajo en tanto que actividad humana que añade valor a la mercancía final, diferenciada del resto de experiencias ${ }^{6}$.

Este trabajo necesario para la producción masiva de mercancías -y para su acumulación en stocks que garantizasen el abastecimiento- requería una relación continuada entre las partes (proveedor de la fuerza de trabajo y proveedor de los medios de producción). En esta lógica se institucionalizó la relación salarial como vinculación económica en torno a la que pivotaría, desde finales del siglo XIX y durante el siglo XX, toda la legislación laboral; una suerte de ciudadanía laboral que, en España, desarrolló sus pretensiones desde las primeras leyes que regulaban determinadas circunstancias atinentes a la actividad laboral ${ }^{7}$ hasta el Estatuto de los trabajadores actual que, como es sabido, se introduce como sigue: «La presente Ley será de aplicación a los trabajadores que voluntariamente presten sus servicios retribuidos por cuenta ajena y dentro del ámbito de organización y dirección de otra persona, física o jurídica, denominada empleador o empresario».

\section{Derecho regulativo fordista}

El derecho laboral, por tanto, comenzó su andadura desde los presupuestos que proponía la economía política, aunque formulado como un modo de remiendo ante las fisuras que, muy tempranamente, dejaba entrever aquella misma ciencia: la mano invisible no se mostró tan eficaz como fue pronosticada y, en esa crisis, irrumpe el derecho laboral como variante del derecho $\mathrm{civil}^{8}$, como extensión de éste hacia ámbitos que, en principio, no

\footnotetext{
${ }^{6}$ Sanchís Gómez apunta que, en general, «las formaciones sociales anteriores [a la sociedad capitalista] no estaban estructuradas por el trabajo y tenían una concepción negativa de lo que hoy entendemos por trabajo» (SANCHÍS GÓMEZ, E. «Concepciones del trabajo: de las ambigüedades medievales a las paradojas actuales», Cuadernos de Relaciones Laborales, v.22, $\mathrm{n}^{\circ} \mathrm{I}$, pág. 38). Basta para ello remitir a la etimología del término en castellano, «del término latino tripalium, que hacía referencia a un instrumento de tres palos usado para atar y proceder a la tortura de los reos y para herrar a los caballos» (SANTOS ORTEGA, A. Y POVEDA ROSA, M. Trabajo, empleo y cambio social, Valencia, Tirant lo blanch, 2002, pág. 27, y SANCHÍS GÓMEZ, «Concepciones del trabajo», cit., pág. 39). Puede considerarse también, según otros autores, aunque con una esencia significativa similar, la etimología procedente «de trabs, trabis, traba, porque es el instrumento de sujeción del hombre» (LASTRA LASTRA, «El trabajo en la Historia», Anuario Mexicano de Historia del Derecho, $\mathrm{n}^{\circ} \mathrm{II}-\mathrm{I} 2$, 2000, pág. I95). De este modo, el trabajo estaba innegociablemente vinculado a la indignidad, evitada por los hombres suficientemente libres como para hacerlo.

${ }^{7}$ La Ley de 24 de julio de 1873 , pionera en el ámbito laboral, aunque de dudosa eficacia, prohibía trabajar a los menores de diez años, así como los trabajos nocturnos a los menores de dieciséis. Cada vez más pormenorizadas se implementaron diversas normativas al respecto: el Código del trabajo de I926, la Ley del contrato de trabajo de I93I, el Fuero del trabajo de I938 o el Reglamento general de seguridad e higiene en el trabajo de i940.

${ }^{8}$ Como parte de los derechos sociales referidos por Marshall en la secuenciación de derechos que realiza en su conferencia de los años cuarenta, teorizando unos trazos jurídicos ya existentes (MARSHALL, T.H., Ciudadanía y clase social, trad. Pepa Linares, Madrid, Alianza, I998).
} 
fueron previstos en las normas constituyentes por los arquitectos del Estado Moderno, por los arquitectos del ciudadano?.

Se trataba, de este modo, de una variante jurídica a modo de derecho crítico que, enmarcado en la lógica trabajadores/empresarios (que evolucionaba la ilusión del mero ciudadano) se desveló útil para la confección de cierta paz social a través de la atribución de derechos y obligaciones a los sujetos presupuestos ${ }^{\mathrm{I}}$. Estos sujetos, por tanto, desarrollarían sus potencialidades en el quicio relativamente estanco del derecho laboral.

Así es como esta rama del derecho se desarrolló -ya en el siglo XIX, aunque sobre todo durante el siglo XX- como una tangente del sistema jurídico global, pionera en asumir concepciones externas a las constituciones jurídicas primigenias -basadas en un sujeto ideal, abstracto, sin significaciones más allá de las que le ponían en una relación de igualdad con el resto de seres humanos ${ }^{\text {II }}$. En el derecho laboral se propusieron las primeras experiencias jurídicas que rompían la integridad del sujeto anónimo ilustrado, tamizado en torno al trabajo por la diferencia que imprimía la economía política entre empresarios y trabajadores.

Esta dicotomía ha sido durante décadas la diferenciación formal que el sistema jurídico ha asumido a partir de los análisis económicos clásicos que, con vocación positivista, trataban de reducir la complejidad de los movimientos de capitales hasta procurar una significación figurativa, observable e incluso predecible.

Esta significación implicaba la proyección de aquella verdad de laboratorio más allá de sus límites económicos, haciéndola observable no ya sólo por los mismos actores (conciencia de clase) ${ }^{12}$, sino también por el político/jurista, supuesto regulador neutral entre

\footnotetext{
${ }^{9}$ «(La Revolución) francesa llega a plantearse nada menos que la recreación del hombre, su nacimiento provocado con riesgo de aborto» (CLAVERO, B., Happy Constitution: cultura y lengua constitucionales, Madrid, Trotta, I997, pág. 33). En cierto modo, proyectando un diálogo ficticio, podríamos añadir que ALONSO, L.E. (La crisis de la ciudadanía laboral, Barcelona, Antrophos, 2007, pág. I7) apunta la permanencia de ese riesgo: «La ciudadanía, más que como una cuestión otorgada -un reconocimiento magnánimo de derechos por los Estados- habría que concebirla, históricamente, como la formación de una identidad activa y conflictiva, una lucha por el reconocimiento efectivo de los derechos, resultado de una permanente movilización social de unos actores que buscan ampliar los límites de su condición realmente existente en cada período histórico».

1o Entendemos el desarrollo del derecho laboral como plasmación institucional de la crítica de la economía política. CLAVERO (Happy Constitution, cit., pág. 20) advierte que, más allá del individuo constitucional, se proyectan una serie de estados personales: «Categorías no son anécdotas. Master and Servant es en Inglaterra rúbrica que identifica el derecho del trabajo en tiempo histórico constitucional. Y coetáneos son maitre et domestique o también amo y criado (...) En lo que toca concretamente a sirvientes, durante el siglo XIX podrá irse contrayendo la relación más doméstica por la más salarial» CLAVERO (Happy Constitution, cit., págs. 29-30). El autor denuncia el tracto preconstitucional de las dicotomías expuestas, sin embargo, encauzándolo en nuestras tesis, advertimos, si acaso, una raigambre cultural de los términos que sólo pudieron nutrirse de sustancia postrevolucionaria adaptándose a las exigencias de la economía política y su crítica, es decir, adaptándose a la criba del nuevo ciclo productivo y sus resistencias.

${ }^{\text {II }}$ Estas constituciones primigenias marcaron el inicio en el desarrollo de la idea de Rule of Law que, sin embargo, sufriría ciertos desajustes: «Cada vez son más los espacios del poder que se escapan al 'imperio de la ley' y al control jurídico» (CALVO GARCÍA, M. «Transformaciones del derecho. Democracia y principio de legalidad en el Estado regulativo», CALVO GONZÁLEZ, J. y MONEREO ATIENZA, C., Filosofía Jurídica $y$ siglo XXI. Ocho panoramas temáticos, Universidad de Málaga, Málaga, 2005, pág.58). Desajustes que, como decimos, produjeron tempranamente en el ámbito de las relaciones laborales las fisuras entre las que se filtró un conocimiento ajeno al derecho.

${ }^{12}$ La conciencia de clase que el marxismo reenvía al proletariado propone una de las escenificaciones épicas que, en clave de teoría de la ciencia, implica la identificación entre sujeto operatorio y objeto operado: «El autoconocimiento del proletariado es, pues, al mismo tiempo, conocimiento objetivo de la esencia de la sociedad. La persecución de los objetivos de clase del proletariado significa al mismo tiempo la realización consciente de los fines evolutivos objetivos de la sociedad, los cuales, empero, no podrían pasar de ser, sin la acción consciente de proletariado, meras posibilidades abstractas y limitaciones objetivas» (LUKACS, G., Historia y consciencia de clase, trad. Manuel Sacristán, Madrid, Sarpe, I984, pág. 88, vol. 2). Y la identificación sujeto/objeto apunta directamente a la problemática de las racionalidades reflexivas, especulativas y contradictorias, como instigadoras de cierta irracionalidad postmoderna. En cierto modo se trata de la crítica
} 
intereses contrapuestos que, por tanto, asumía estructuras externas a la racionalidad formal del derecho como sistema ciego, inhábil para discernir diferencias entre seres humanos ${ }^{\mathrm{I3}}$.

El derecho laboral representaba una representación ya operada en otros ámbitos nótese la necesidad de la redundancia-, como literatura referida a verdades precedentes, como lenguaje hipervinculado cuya función se reducía, esencialmente, a regular y poner en relación conceptos captados del exterior ${ }^{\mathrm{I}}$. El derecho referido al trabajo proyectaba cauces y forjaba equilibrios entre actores y elementos predeterminados. Se trataba, de este modo, de uno de los primeros campos sociales apropiado para el desarrollo de un derecho regulativo ${ }^{15}$, desarrollado a partir de las estructuras de conocimiento que se generaron al margen de la producción endógena del propio derecho en tanto que ámbito diferenciado ${ }^{\mathrm{T} 6}$.

Este equilibrio ordenado desde el ámbito jurídico operaba, igualmente, como uno de los modos sociales para poner en común aquellas potencialidades productivas radicadas en los cuerpos de los individuos, es decir, para dotar de sentido a la actividad emanada de los trabajadores, encarrilada en empresas jerarquizadas y, por tanto, en procesos racionales determinados a la consecución de un objeto/mercancía ${ }^{\text {I7 }}$.

Todo, incluso la lucha obrera, parecía enclaustrado en un universo armónico, como negociaciones hacia un innegociable horizonte pacífico ${ }^{\mathrm{r} 8}$. Fuera como fuese, el objeto/mercancía debía ser producido.

básica inherente a la posibilidad actual de una ciudadanía laboral: la ciudadanía pretende una universalidad objetiva y pacífica que niega lo laboral en tanto que conflicto subjetivo por definición científica; Queda como especulación no atinente a este artículo si la crisis en la que se encuentra hoy la ciudadanía laboral (ALONSO, La crisis de la ciudadanía laboral, cit.) debe superarse bien mediante modificaciones sobre ese mismo concepto o bien mediante alternativas a la centralidad de lo laboral.

${ }^{13}$ «Las funciones que se asignan al derecho y al Estado en la ideología jurídica liberal tendrían como único fin la consolidación y aseguramiento de un marco racional-formal de autonomía protegida. El Estado sólo tendría funciones negativas, de mero arbitrio del juego social» (CALVO GARCÍA, «Transformaciones del derecho», cit., pág. 6o). De este modo, «El derecho surge y evoluciona como un sistema racional (...) y al mismo tiempo formal» (CALVO GARCÍA, «Transformaciones del derecho», cit., pág. 62).

${ }^{14}$ En este sentido, el derecho laboral se propuso en modos y formas que visibilizaron tempranamente el irremediable fracaso del formalismo jurídico estricto: «El formalismo jurídico y la ilusión metodológica que lo complementa buscan conservar o crear ámbitos de racionalidad formal, esto es, neutrales, que aíslen la decisión jurídica del pluralismo de otros ámbitos sociales y en especial de la política. De esta manera, se produce una apariencia de falsa legitimidad de las dinámicas jurídicas, al margen de cualquier factor político, económico o social. Una ilusión que estaría irremediablemente condenada al fracaso» (CALVO GARCÍA, «Transformaciones del derecho», cit., pág. 64).

${ }^{15}$ «Este derecho útil o derecho regulativo se caracteriza por estar profundamente penetrado por criterios y determinantes de índole material: económicos, políticos, axiológicos, técnicos, etc. » (CALVO GARCÍA, «Transformaciones del derecho», cit., pág. 67). Se trata del «desplazamiento del derecho desde el ámbito de la racionalidad formal soñado por el liberalismo hacia nuevas formas de racionalidad sustantiva» (CALVO GARCÍA, «Transformaciones del derecho», cit., pág. 68).

${ }^{16}$ Otras ramas del derecho comenzarían a implementar estas técnicas años más tarde: el derecho penal, por ejemplo, comienza a asumir las estructuras que la estadística sociológica apunta para etiquetar (Véase la obra que, durante los años sesenta, desarrolla BECKER, H.S., especialmente Outsiders: hacia una sociología de la desviación, trad. Jaime Arrambide, Buenos Aires, Siglo XXI, 2009) y, por tanto, diferenciar individuos que proyectan perfiles de riesgo más probable, generando un derecho penal previsor que rasga, así, la idealidad de un sujeto universal.

${ }^{17}$ El derecho regulativo busca fines, no sigue lógicas deductivas estrictas: «modelo caracterizado por la orientación substantiva del derecho hacia fines regulativos y resultados prácticos» (CALVO GARCÍA, «Transformaciones del derecho», cit., pág. 67).

${ }^{18}$ Negociaciones que introducen nuevos criterios («imperativos éticos, terapéuticos, conveniencias e intereses profesionales y políticos»-CALVO GARCÍA, «Transformaciones del derecho», cit., pág. 7I), negociaciones enmarcadas en exigencias de responsabilidad (responsive law -CALVO GARCÍA, «Transformaciones del derecho», cit., pág. 67). Se trata, en definitiva, de la responsabilidad derivada de conservar aquel horizonte pacífico, aceptado estratégicamente incluso por la crítica de la economía política más 


\section{Crisis del fordismo y giro lingüístico de la economía ${ }^{19}$}

Sucede, sin embargo, sobre todo a partir de los años setenta, que la racionalidad incólume desplegada por el fordismo comienza a agrietarse. El perpetuum mobile keynesiano parecía desacelerarse conforme la ley de rendimientos decrecientes del capital actualizaba sus supuestos $^{20}$. La ampliación del mercado que se operó durante el fordismo encontró sus límites (¿naturales?) $)^{21}$ cuando el ejército de consumidores desbordó a su correlato de trabajadores implicados directamente en la producción.

El consumo seguía proponiéndose como fundamento de la expansión del capital, aunque ya no tanto extensiva como intensivamente ${ }^{22}$; En paralelo, el abaratamiento de costes no dejaba de proponerse como frente de competencia entre empresarios (debía abaratarse el precio de la mercancía más de lo que lo hacía el competidor), así como de lucha entre empresarios y obreros (debía abaratarse el salario sin que los obreros propios llegasen a ser contraproducentes). Esta tensión -dialéctica o devenida sin síntesis válidas, como momentos espectaculares de una lucha continuada- sólo pudo resolverse a través de las escapatorias de capital articuladas a partir de los años setenta $^{23}$, naturalizándose paulatinamente la destrucción de empleos debida a la maquinización ${ }^{24}$ o deslocalización de los procesos manufactureros.

radical y quebrantado, si acaso, por el momento revolucionario, transformador, que Engels trasponía desde las ciencias de la naturaleza (ENGELS, F., Introducción a la dialéctica de la naturaleza; El papel del trabajo en la transformación del mono en hombre, Madrid, Ayuso, 1974).

${ }^{\text {19 }}$ Expresión tomada del subtítulo del libro El sitio de los calcetines, de Christian Marazzi, que trata de recoger críticamente la obra de Habermas en lo que se inserta en la tradición del giro lingüístico y compromete al lenguaje como base de la política, como modo de «ir más allá del puro y simple dato, más allá de la dura y cruda norma, más allá de elemento meramente técnico-instrumental» (MARAZZI, El sitio de los calcetines, cit., págs. 23 SS.).

${ }^{20}$ RICARDO, D., Principios de Economía Política y Tributación, trad. E. Hazera, Barcelona, Orbis, I985, págs. I24 SS.

${ }^{21}$ Hasta cierto punto pudo seguir operando la ficción smithiana (y ricardiana) por la que la racionalidad de la economía se basaba en el criterio de la subsistencia, una suerte de pauta natural al ser humano que marcaba réditos, beneficios y salarios: «La economía política, considerada como una rama de la ciencia del hombre de Estado o legislador, se plantea dos objetos distintos: en primer lugar conseguir un ingreso o una subsistencia abundantes para el pueblo, o más precisamente que el pueblo pueda conseguir ese ingreso o esa subsistencia por sí mismo» (SMITH, A., Una investigación sobre la naturaleza y causas de la riqueza de las naciones, trad. Carlos Rdguez. Braun, Madrid, Tecnos, 2009, pág. 505). Tal vez, partiendo de esa literatura inestable que refiere una subsistencia abundante, el fordismo fue dando cuenta de la impostura, reinventando el deseo del consumidor y produciendo mercancías inimaginables antes de ser proyectadas por las agencias creativas, capaces de naturalizar cualquier producto en la cotidianeidad de la clase media, tendencia que se visibilizó inequívocamente durante los años sesenta del siglo XX.

${ }^{22}$ En el sentido de BAUDRILLARD, J. (La sociedad de consumo: sus mitos, sus estructuras, trad. Alcira Bixio, Madrid, Siglo XXI, 2009, págs. 39 ss.), tomando el consumo como una lógica social, casi como una violencia, como una búsqueda eterna: «Todo el discurso sobre las necesidades se basa en una antropología ingenua: la de la propensión natural del ser humano a la felicidad».

${ }^{23}$ En España este viraje en el ciclo productivo comienza a notarse con las primeras reformas laborales de los ochenta, incoándose el proceso de reconversión de la economía.

${ }^{24}$ Se corrobora plenamente la deriva apuntada por Marx en los Grundisse (cit. en LAZZARATO, Lavoro immateriale. Forme di vita e produzione di soggettività, Verona, Ombre Corte, I997, págs. 25 ss.) a la vista del ciclo de producción industrial decimonónico, del que pudo deducir que la creación de riqueza dependía no tanto del tiempo de trabajo efectivo desempeñado por un trabajador, sino de la calidad (hipotecada al desarrollo de la ciencia e implementación de tecnologías) de ese tiempo de trabajo y, por lo tanto, de la ingeniería (o trabajo muerto del ingeniero, en sentido amplio) implícita en las máquinas o en la misma organización grupal de los trabajadores. De este modo, podemos decir que la acumulación de trabajo muerto en los procesos laborales determina un trabajo vivo absolutamente mediado y relacionado mucho más complejamente con la realidad última que supone la mercancía. 
Los trabajadores del fordismo se extinguían (se extinguen) y la tipología del trabajo se reinventa ${ }^{25}$, conformándose una suerte de trabajadores inmateriales, responsables de sus pequeños mundos delegados, que gestionan -de modo más o menos indirecto- la riqueza material manufacturada en el afuera (periferia del mundo) o los servicios inmateriales que hacen más soportable el adentro (democracias desarrolladas).

El fordismo, en definitiva, cada vez se comporta de modo menos mecánico, menos predecible, sintomatizando cierto agotamiento gradual. Las grandes plantillas laborales, las fábricas en las que se representaba la diferenciación figurativa clásica, son cada vez menos necesarias. La economía política parece perder sus elementos básicos de cálculo. El progreso unívoco que apuntaba la dialéctica social trabajadores/empresarios parece tomar derivas inciertas, rumbos no cartografiados. Irracionalidades.

Se trata de esas irracionalidades derivadas del abandono que hace el sujeto de su posición externa -observadora- respecto de los procesos fabriles determinados, automatizados y previsibles; El sujeto productor -que confecciona objetos externos a él- se transfigura en objeto producido por otros sujetos que son, a su vez, objetos. El sujeto, por tanto, es reificado en la medida en que su cuerpo -otrora desnudez dispuesta para la cooperación en estructuras externas al mismo- es el campo de sustanciación de saberes y habilidades.

Es la reificación ${ }^{26}$ codificada en los currículos y en las biografías, en la formación y en las destrezas, en las artes y en las gracias mediante las que los sujetos se proyectan al mundo. Es el sujeto como mercancía. Es la mercancía orgánica, como sujeto que produce ${ }^{27}$. Es la indistinción interna de un proceso circular reproductivo que inhabilita cercamientos válidos para procesar o conocer desde fuera ${ }^{28}$.

Se trata, por tanto, de la universalidad en crisis, de la imposibilidad de mantener circuitos cerrados de razonabilidad, de las grietas cada vez más visibles en esos habitáculos estancos que eran las disciplinas y los procesos. Las divisiones del saber y del proceder, distinguibles y relativamente pacíficas durante el fordismo, se muestran ahora violentadas y cruzadas complejamente. Las proposiciones científicas, las estructuras repetidas y previsibles -antes irrefutables- son puestas en crisis con la facilidad de la literatura

\footnotetext{
${ }^{25}$ En cierto modo, se trata de aquella destrucción creativa shumpeteriana (SCHUMPETER, J.A., Capitalismo, socialismo y democracia, Barcelona, Folio, I984, págs. II8 ss.) que CORSANI, A. («Hacia una renovación de la economía política. Antiguas categorías e innovación tecnológica», en BLONDEAU, O., WHITEFORD, N.D., VERCELlONE, C., KYROU, A., CORSANI, A., RUlLANI, E., MOUliER BOUTANG, y., LAZZARATO, M., Capitalismo cognitivo, propiedad intelectual y creación colectiva, trad. Emmanuel Rodríguez López, Beñat Baltza, Antonio García Pérez-Cejuela, Madrid, Traficantes de sueños, 2004, pág. 96) reinventa como proceso de creación destructiva, basado en la idea de que no sucede ya una innovación derivada de lógicas empresariales, sino una selección de innovaciones válidas en un océano de innovaciones propuestas por trabajadores del conocimiento. No se trata, por tanto, de la sustitución de trabajos desfasados según una idea empresarial que inventa deductivamente nuevas funciones, sino la destrucción de ideas que, propuestas desde abajo por el cognitariado, no son elegidas para ser financiadas por el empresario-financiero. El cognitariado, por tanto, debe reinventar constantemente su función, su posición productora de posibilidades.

${ }^{26}$ Reificación elogiada por Virno (VIRNO, P., Cuando el verbo se hace carne. Lenguaje y naturaleza humana, trad. Eduardo Sadier, Madrid, Traficantes de sueños, 2005, págs. I45 Ss.) si aplicada a objetos que no afectan al mundo, manteniéndose en sus quicios, finitos y consumibles, extraños a estos ciclos reproductivos sin límites señalados.

${ }^{27}$ «Producer and product are both subjects: humans produce and humans are produced» (HARDT, M. y NEGRI, A., Commonwealth, Cambridge, The Belknap Press of Harvard University Press, pág. I36).

${ }_{28}$ Lyotard, uno de los primeros relatores de esta desorientación, advierte que se trata del fin de los metarrelatos, una nueva época en la que la parafernalia ilustrada parece desmoronarse: En la medida en que la modernidad era analizada en términos de objeto unitario, los marcos de racionalidad eran comunes: «se adivina una misma idea de lo social: que la sociedad es una totalidad unida, una 'unicidad' (...) De ahí su credibilidad: al contar con los medios para hacerse realidad, esa credibilidad cuenta con los de administrar sus pruebas. Lo que Horkheimer llamaba la 'paranoia’ de la razón» (LYOTARD, La condición postmoderna, cit., pág. I3).
} 
irreverente, del talento creativo capaz de inventar formas más adaptadas, nuevas figuraciones más eficaces en un marasmo de partículas incognoscibles y libres de pertenencias ontológicas ${ }^{29}$.

Roto el equilibrio keynesiano, la pauta de negocio pasa por inventar equilibrios renovados, efímeros, coyunturales que, aun escapándose a la lógica estructuralista, mantengan dinámico el ciclo productivo ${ }^{30}:$ «Sin innovación no hay futuro» ${ }^{3 \mathrm{I}}$. Y la invención de equilibrios renovados - sin necesidad de amparo científico- pasa por la capacidad performativa del lenguaje como esa tecnología primigenia que recrea el mundo a cada instante $^{32}$ : «La entrada de la comunicación, y, por lo tanto, del lenguaje en la esfera de la producción constituye, de hecho, el verdadero origen del giro decisivo que, lo queramos o no, caracteriza el presente» ${ }^{33}$.

Pero la remisión al lenguaje desborda el análisis clásico de la ideología circunscrita al juego político ${ }^{34}$; la interpelación del lenguaje remite a la misma epistemología transdisciplinar de los tiempos ${ }^{35}$ : Y es que, si la ideología implicaba la adopción de uno de los metarrelatos en juego (pongamos, por referir el más maniqueo, capitalismo/socialismo real), el giro lingüístico de la economía, sin embargo, refiere la misma conceptualización y, por tanto, no se desvela como dicotomía de metarrelatos, sino que se propone como compartimentación natural que surge desde abajo, que surge de la interpretación que el individuo libre $y$ formado realiza de lo real: El individuo ya no se inserta en una creencia sin fisuras, en un ejército de dogmas, sino que, a falta de un corpus de referencias válidas, duda, ensaya, experimenta. El individuo -que ya no vive para trabajar o trabaja para vivir, sino que vive/trabaja- propone constantemente nuevas experiencias vitales, laborales, (re)productivas, que son la base para la nueva economía: se aceptan y promocionan las experiencias más interesantes, proponiéndose como conceptos que reconstruyen las perspectivas, como neologismos (y, por lógica de dominación cultural, anglicismos) que reinventan el terreno y se proyectan como posibilidades antes no contempladas ${ }^{36}$.

La ideología se negociaba entre embajadores, se contrariaba en campos de batalla, se proponía en panfletos, se adoptaba por los militantes a tiempo completo, se imponía

\footnotetext{
${ }^{29} \mathrm{Y}$ es que, si la ciencia surge a partir de un relato primigenio, habilitador, si la ciencia presupone el relato (LYOTARD, La condición postmoderna, cit., págs. 25-26), era cuestión de tiempo que éste traicionase a aquélla. Básicamente porque, llegado el momento de desarrollo suficiente de las ciencias, llegada la modernidad y la autonomía de las disciplinas, éstas se desarrollan conforme a la reciprocidad señalada por Lyotard: «No hay técnica sin riqueza, pero tampoco hay riqueza sin técnica». De este modo «la ciencia se convierte en una fuerza de producción, es decir, en un momento de la circulación del capital (...) La administración de la prueba (...) pasa así bajo el control de otro juego de lenguaje, donde lo que se ventila no es verdad, sino la performatividad.» (LYOTARD, La condición postmoderna, cit., pág. 37). Es decir, la ciencia crea las verdades necesarias: la ciencia, como cualquier otro relato, crea una realidad. Toda realidad, en definitiva, deviene relato en este nuevo marco conceptual.

${ }^{30}$ Y ésta puede ser la nueva y única estructura válida: mantener dinámico el ciclo productivo; Así, invirtiendo la concepción referida de BATAILLE (La parte maldita, cit., 25 ss.), la irracionalidad económica sería un estado de las cosas coyuntural, inserto en aquel marco de racionalidad global del capital.

${ }^{31}$ Lema de la Fundación riojana para la innovación.

${ }^{32}$ VIRNO, Cuando el verbo se hace carne, cit., págs. 4I Ss.

${ }^{33}$ MARAZZI, El sitio de los calcetines, cit., pág. 7.

${ }^{34}$ La producción social en el lenguaje era desvelada por Marx como producción de ideología (LAZZARATO, Lavoro immateriale, cit., pág. I7).

${ }^{35}$ «El lenguaje no reproduce, sino que distorsiona la realidad que, sin embargo, no tiene otra forma de anunciarse más que en la distorsión del lenguaje» (GALIMBERTI, U., cit. en MARAZZI, Lavoro immateriale, cit., pág. 26).

${ }^{36}$ «Los objetos sociales están siempre (...) constituidos por hechos sociales; y en cierto sentido, el objeto no es sino la posibilidad continuada de la actividad» (SEARLE, J.R., La construcción de la realidad social, trad. Antoni Domènech, Barcelona, Paidós, 2004, pág. 54).
} 
como necesidad de guerra (fría o no). La ideología recaía sobre los individuos. La conformación conflictiva de los conceptos, sin embargo, surge desde los individuos, de cada experiencia observadora y, si acaso, se filtra convenientemente por procesadores que son las nuevas maneras del poder. Procesadores que no se concentran, necesariamente, en soberanías definidas: actúan en los campos económico, político, periodístico, artístico, publicitario, religioso... campos comunicativos que relajan sus fronteras hasta confundir diálogos, enunciados, propuestas y legitimidades. Campos entre los que destaca, como queda por ver, el derecho. Se trata, por tanto, de un ejercicio conceptológico; ya no quedan ideologías por las que discutir porque la única ideología es la que reinventan a cada momento los conceptos.

\section{Crisis del objeto regulado: crisis del concepto trabajo}

Hemos visto cómo la crisis de la modernidad irrumpe con descarnada evidencia en el ámbito que marcaba la vieja economía política. El síntoma más traumático de esta irrupción es, sin duda, la desestructuración de uno de sus elementos fundamentales: el trabajo.

El concepto trabajo que abarca esas experiencias hoy conocidas como tales se remonta a aquellos primeros estudios de los economistas políticos clásicos: Smith, en su análisis de la producción de la riqueza de las naciones ${ }^{37}$, aísla el concepto como en un tubo de ensayo, proponiendo la verdad del trabajo como diferenciación válida de experiencias y, por tanto, de posibilidades futuras: el súbdito campesino, rutinariamente protegido a cambio de una parte de su cosecha, se transforma en ciudadano, libre de trabajar (o no).

Y el trabajo, aislado en su abstracción científica, desborda los marcos de estudio fisiocráticos apegados a la fertilidad de la tierra ${ }^{3^{8}}$ y se sustancia en multitud de trabajos concretos, tendencialmente fabriles que, en todo caso, añaden valor a determinada mercancía final. La paz de esta univocidad científica se mantiene hasta que el fordismo se agrieta, filtrándose entre sus hendiduras una nueva época:

En los tiempos postfordistas, la característica crucial que sobreviene a las actividades que añaden valor a la mercancía es la inmaterialidad ${ }^{39}$. Esta especificidad de las labores actuales -que resitúa por completo la concepción del trabajo- puede comprenderse fundamentalmente a través de una doble perspectiva:

(I) Fenoménicamente puede constatarse un aumento de la labor mediada por las máquinas, sean grandes medios de producción o pequeños centros informacionales (personal computer) que, a modo de cajas negras, obtienen, procesan y transmiten información (o ejecutan físicamente la orden) que agrega valor en el proceso productivo. La comunicación simbólica $^{40}$ con estas máquinas canaliza, en la gran mayoría de los trabajos actuales, la intervención del trabajador en el proceso productivo, separándole cada vez más de la materia prima y del producto final.

(2) No sólo es inmaterial el trabajo de mediación con la mercancía a través de las máquinas y sus procesos input/output, sino que resulta igualmente separado de la materia

\footnotetext{
${ }^{37}$ SMITH, Una investigación sobre la naturaleza y causas de la riqueza de las naciones, cit.

${ }^{38}$ NAPOLEONI, C., Fisiocracia, Smith, Ricardo, Marx, Barcelona, Oikos-Tau, I974.

${ }^{39}$ LAZZARATO, Lavoro immateriale, cit., págs. 23 ss.

${ }^{40}$ «Este tipo de lenguaje debe ser lo más formal posible, es decir, debe tratarse de un lenguaje hecho de símbolos, signos y códigos abstractos, condición indispensable para permitir que todos los que colaboran en el seno de la empresa puedan interpretarlos al instante sin titubeos» (MARAZZI, El sitio de los calcetines, cit., pág. 22)
} 
el trabajo -cada vez más común- dedicado a la reinvención del campo por el que han de discurrir las mercancías o los servicios, sea a través de la publicidad, sea a través de estrategias de distribución, comercialización o puesta en práctica de sugestiones y afectos.

Con base en estos presupuestos iniciales, las derivas del sistema económico apuntan a lo que algunos autores sintetizan como capitalismo cognitivo ${ }^{4 \mathrm{r}}$, cuyo correlato despolitizado, desarrollado en los ámbitos legales, es el que lo titula economía de la información o sociedad del conocimiento.

Para que el mercado basado en los conocimientos y en la innovación constante se mantenga vivo y dinámico, los individuos no pueden operar confiados en su propia fuerza de trabajo como potencia innata e inmediatamente vendible, sino que se hace necesaria una actualización constante de sus posibilidades, procesada en esferas de cooperación, de puesta en común de saberes, tecnologías o modos organizacionales. Se trata de lo que emblemáticamente puede titularse la comunità di lavoro ${ }^{42}$, ya que la innovación capaz de servirse de referencias externas se muestra superior al desarrollo de fórmulas en un sistema estanco, ordenado pero cerrado a las capacidades que quedan fuera del perímetro.

De este modo, las viejas disciplinas empresariales, basadas en la transmisión de un conocimiento primigenio que, desde la cúspide, va empapando al resto de la plantilla laboral, se desvelan ineficaces y mucho menos fértiles que el modo cooperativo/creativo que traslada la necesidad de innovación al trabajador ${ }^{43}$, al cognitariado ${ }^{44}$ (o proletariado del conocimiento) capacitado y estimulado para absorber y procesar referencias externas, dispuesto para una continua implementación de prolíficas novedades ${ }^{45}:$ «una trayectoria que primero convirtió al profesional liberal en profesional funcional (al servicio de una gran organización económica), y de éste, al profesional consultor -vendedor de estrategias a corto plazo de una organización a otra $-\gg^{46}$. Se manifiestan contraproducentes, por tanto, las grandes plantillas laborales preparadas para reproducir mecánicamente -sin más arte ni

${ }^{41}$ Mediado por la centralidad asumida por los mercados financieros, Fumagalli propone un término aún más evolucionado, continente de mayor complejidad: «Los mercados financieros son hoy el corazón pulsante del capitalismo. Y lo son más cuanto más se basen los procesos de acumulación y de valorización capitalista sobre la explotación del conocimiento y de la vida. Éste es el tema del presente libro, proporcionar algunos instrumentos para tratar de comprender el nuevo paradigma de producción y de mercado, que llamamos capitalismo cognitivo y bioeconomía (en una palabra bio-capitalismo)» (FUMAGALLI, A., Bioeconomía y capitalismo cognitivo. Hacia un nuevo paradigma de acumulación, Traficantes de Sueños, Madrid, 20ıо, pág. I9).

${ }^{42}$ LAZZARATO, Lavoro immateriale, cit., pág. Io.

${ }^{43}$ Como apunta Lazzarato, «il modo di produzione post-fordista non può essere semplicemente descritto come 'produzione flessibile' (...) ma prima di tutto come una attivazione di differenti modi di produzione ('materiali' e 'immateriali')» (LAZZARATO, Lavoro immateriale, cit., pág. 2I).

${ }^{44}$ Término propuesto por Franco Berardi (BERARDI, F., La fábrica de la infelicidad. Nuevas formas de trabajo $Y$ movimiento global, Traficantes de Sueños, Madrid, 2003).

${ }^{45}$ «En el modelo de gestión tradicional, la empresa tomaba como unidad de medida del producto y el puesto de trabajo; pensaba en términos de organigrama y cadena de montaje, de gestión de stocks, de difusión de las informaciones dentro de una pirámide burocrática, de ritmo secuencial. Ahora, los esquemas de acción pasan a observar el servicio que presta a los individuos, un servicio que incluye el producto pero no se limita a él; así, sus relaciones y valoraciones financieras se convierten en primordiales» (ALONSO, La crisis de la ciudadanía laboral, cit., pág. 80). Paralelamente, este nuevo modo de organización laboral «svuota e delegitima le funzioni di comando dell'imprenditore e dello Stato» (LAZZARATO, Lavoro immateriale, cit., pág. II), ya que «il ciclo del lavoro immateriale è precostituito da una forza lavoro sociale e autonoma, capace di organizzare il proprio lavoro e le proprie relazioni con l'impresa. Nessuna 'organizzazione scientifica del lavoro' può predeterminare questa capacità e questa creatività produttiva sociale» (LAZZARATO, Lavoro immateriale, cit., pág. 25). «la creación y la efectuación de los mundos (la creación y consumación de lo sensible) preceden y exceden la división del trabajo. La expresión y la constitución de las maneras de sentir, en lugar de depender del modo de producción, son previas al funcionamiento de la economía. Esta es la precaución con la que hay que leer las líneas que siguen, ya que a partir de esta concepción de la cooperación se puede pensar una economía de los afectos, una economía de lo sensible.» (LAZZARATO, M., Por una política menor. Acontecimiento y política en las sociedades de control, trad. Pablo Rodríguez, Madrid, Traficantes de sueños, 2006, 52).

${ }^{46}$ ALONSO, La crisis de la ciudadanía laboral, cit., pág. 77. 
inventiva que la ya conocida- una sola mercancía. Se inhabilita así, cada vez más, la dicotomía empresarios/trabajadores ${ }^{47}$. Y de esa inhabilitación procede toda una batería de medidas desregulativas que descuelgan las relaciones laborales de las verdades económicopolíticas vinculadas a un ciclo productivo agonizante.

La hegemonía del trabajo inmaterial en el nuevo ciclo productivo trata, por tanto, de aprovechar cada externalidad ${ }^{48}$, ya que «è la comunita in quanto tale che l'organizzazione post-fordista sfrutta ${ }^{49}$. Debe subsumirse, por tanto, en la lógica productivista todo componente social identificable o susceptible de ser concebido como tal: elementos lingüísticos, relacionales sexuales, capacidades físicas, e incluso defectos, imperfecciones o desastres espectacularizables.

Así, en el postfordismo de las sociedades occidentales hiperdesarrolladas (y a occidente pueden ser reconducibles las tendencias del mundo ${ }^{50}$ el trabajo que, en su sentido clásico, se desarrollaba enclaustrado en un espacio físico concreto, evoluciona hacia una suerte de renovación de la vita publica en cuanto tal ${ }^{5 \mathrm{I}}$. A fin de cuentas, en estas nuevas coordenadas, toda la población añade valor, toda la población asume el oficio político en tanto que negocia apariencias o gestiona conocimientos. Toda la población acumula y, en la medida de lo posible, mercadea con saberes y posiciones. Resulta complicado existir sin valorizar, existir sin trabajar y, recíprocamente, resulta complicado encontrar características diferenciadoras del trabajo en sí; Resulta difícil reconocer fenoménicamente el trabajo. Resulta difícil la abstracción misma del trabajo. Resulta hasta relativamente arbitrario hablar de trabajo ${ }^{52}$.

${ }^{47}$ ¿Acaso los empresarios no se consideran trabajadores ideales? En una producción sin patrones de comportamiento no sirven sujetos patrones que los impongan formalmente.

${ }^{48}$ Tan pleno es el aprovechamiento que el concepto gasto improductivo (BATAILLE, La parte maldita, cit., págs. 25 Ss.) parece carecer actualmente de cualquier referencia real.

49 LAZZARATO, Lavoro immateriale, cit., pág. I2.

${ }^{50} \mathrm{Si}$ bien Callinicos apunta que «la transición de la manufactura a los servicios no es universal», habiéndose producido un «considerable crecimiento de la clase obrera industrial a escala global» (CALLINICOS, A., Contra el postmodernismo: una crítica marxista, trad. Magdalena Holguín, Bogotá, Ancora I994, págs. 233 ss.), no es menos cierto, como sostienen Hardt y Negri, que «el trabajo inmaterial ha pasado a ser hegemónico en términos cualitativos, y marca la tendencia a las demás formas de trabajo y a la sociedad misma» (HARDT, M y NEGRI, A., Multitud. Guerra y democracia en la era del Imperio, trad. Juan Antonio Bravo, Barcelona, Debate, 2004, pág. I38); Para ello afirman seguir el método de Marx, que «implica alejarse de las teorías de Marx, en la medida en que ha cambiado el objeto de su crítica, la producción capitalista y la sociedad capitalista en su conjunto» (HARDT y NEGRI Multitud, cit., pág. I72). Así, si «en los siglos XIX y XX, el trabajo fabril fue hegemónico en la economía global, aun sin dejar de ser minoritario en términos cuantitativos con respecto a otras formas de producción, como la agrícola (...), en los últimos decenios del siglo XX, el trabajo fabril perdió su hegemonía y en su lugar emergió el «trabajo inmaterial», es decir, el trabajo que crea bienes inmateriales, como el conocimiento, la información, la comunicación, una relación o una respuesta emocional» (HARDT y NEGRI Multitud, cit., pág. I36). Sin embargo, coincidimos con ALONSO (La crisis de la ciudadanía laboral, cit., pág. 20), en que no necesariamente el campo de batalla debe trasladarse por completo al plano comunicativo, ya que el campo de batalla es complejo, cruzado y está lleno de asalariados ordenados por un metarrelato regulativo aún en liza.

${ }^{51}$ La vita contemplativa se contraponía a la vita activa, esa que, durante todo el Medioevo y hasta el comienzo de la Edad Moderna, sólo podía entenderse en un sentido negativo, como «in-quietud», como generador de artificios frente a la belleza natural, divina (ARENDT, H., La condición humana, Barcelona, Paidós, I998, pág. 28). El trabajo, por tanto, era el modo de transformar la perfección dada por Dios a los hombres; se trataba, en definitiva, de un modo de ultraje. Sucede en el postfordismo que se relajan las fronteras entre aquellas vidas, activa del trabajador stricto sensu y contemplativa del servidor público. La praxis y la poiesis aristotélicas (acción con fin en sí misma la primera, acción transitiva la segunda-YARZA, I., «Sobre la praxis aristotélica», Anuario Filosófico, $\mathrm{n}^{\circ}$ I9, I986, págs. I35-I53) parecen perder sus quicios contenedores, enmarañándose la acción inmanente -propia de la praxis ética inyectada en los cuerpos por el protestantismo protocapitalista- con la techné, con el arte, con el talento propio de quien crea y desarrolla poética (poiesis).

${ }^{52}$ Se trata, en cierto modo, de «la limitada capacidad de nuestro lenguaje para expresar la construcción de realidades sociales cuando éstas son percibidas de manera novedosa» (TEUBNER, G., «El derecho como sujeto epistémico», Doxa, n²5, 1989, pág. 10). 
Esta invasión absoluta de la lógica del capitalismo cognitivo alcanza, de este modo, el propio desarrollo vital, irrumpiendo incluso en la misma función del lenguaje como elemento básico creador de comunidad. La producción social en el lenguaje desvelada por Marx como producción de ideología ${ }^{53}$ desborda los límites políticos para calar la misma epistemología de los tiempos. La fijeza lingüística consagrada en el estructuralismo se muestra inhábil ante las nuevas tendencias del ciclo productivo; La gramática fija no puede contener la creación constante de significado que requiere el dinamismo capitalista, resultando constantemente violentada por el trabajo vivo.

La estructura del lenguaje que compartimenta la comprensión del mundo en secciones estáticas está en crisis: El lenguaje está sometido, más que nunca, al imperativo renovador y su implicación en el mundo del trabajo revierte en una superación constante de los oficios tasados, de las actividades tipificadas para transformar la naturaleza conforme a unos parámetros que la economía política remitía a estándares de subsistencia. El estándar se supo impostura y, entrado el siglo XX, se transformó en bienestar, ese concepto incierto que, paulatinamente, fue modificando sus rasgos hasta trocarse hedonismo: creatividad consumible, poiesis práctica, praxis poética, superación constante. La vida puede disfrutarse tanto como pueda narrarse la posibilidad de sentir placer y, por tanto, esa posibilidad debe trabajarse ${ }^{54}$.

El trabajo, de este modo, se ejercita con la fineza, la sutileza y el interés con que se practica el arte; el trabajo se vincula a la capacidad para relatar sensaciones posibles y a la capacidad comunicativa para convertirlas en objetos (servicios) de deseo $0^{55}$. «Il linguaggio e la competenza comunicativa nello stesso tempo in cui, nelle condizioni del general intellect, aprono al 'miracolo' (evento) di un 'atteso imprevisto' e ad una arte del possibile, riproducono anche le condizioni dell'eterno ritorno' del valore e del comando capitalistico» ${ }^{56}$.

En este sentido, la sociedad postmoderna que encuadra una nueva tipología de trabajo se ha convertido en un escenario de representaciones que estimulan una búsqueda constante de aquel sentimiento oceánico que, en terminología freudiana ${ }^{57}$, experimenta el niño en continuidad ininterrumpida con la naturaleza y para quien el mundo es un todo ilimitado, sin afuera, sin compartimentaciones y sin verdades, inagotable y eternamente consumible. Como una distopía viciosa que acoge el debate del lenguaje, es decir, coloquios sobre coloquios sin trincheras ideológicas: el peligro del fin -recurrente- de la historia ${ }^{58}$. La postmodernidad como retorno.

${ }^{53}$ LAZZARATO, Lavoro immateriale, cit., pág. I7.

${ }^{54}$ Muchos de los debates socio-políticos actuales se construyen sobre esta falla que separa la concepción moderna del bienestar y las derivas postmodernas hacia la búsqueda continua del placer como único fin: ¿Qué separa la necesidad del capricho?, ¿qué debe financiar el Estado del bienestar y qué debe dejarse a la empresa del hedonismo?

${ }^{55}$ Esta tendencia rupturista invade los espacios publicitarios, en los que cada producto es reinventado más allá de su definición primigenia, basada en sus elementos constituyentes y tasables. Todo se vende desbordando los quicios de cualquier funcionalismo y las mercancías/servicios ya no son promocionadas conforme a una tasación de las ventajas aplicadas a necesidades primarias (o secundarias), sino como vehículos hacia cierta neoaristocracia consumista de corte nietszchiano. No se trata de una promoción amplificada, sino de una verdadera renovación epistemológica.

${ }^{56}$ LAZZARATO, Lavoro immateriale, cit., pág. I8. El mismo autor advierte, además, la pertinencia del sensible no empírico de Leibniz como narración ilustrativa para los tiempos actuales (LAZZARATO, Lavoro immateriale, cit., pág. 19).

${ }^{57}$ FREUD, S., El malestar en la cultura $y$ otros ensayos, Madrid, Alianza, I980.

${ }^{58}$ Como ya relatase FUKUYAMA, F. (The end of History and the Last Man, New York, The Free Press, I992). 


\section{Derecho laboral postregulativo}

Partiendo de estos presupuestos mínimos, la cuestión polémica emergente en reacción con la interpretación socio-económica expuesta en los epígrafes anteriores remite a un problema clásico del derecho que, sin embargo, sufre cierta agudización tal vez fatal: las posibilidades de adaptación del sistema jurídico a su entorno ${ }^{59}$.

La dificultad con la que ahora se encuentra el derecho laboral es un grado mayor que aquélla con la que se encuentran otras ramas jurídicas: y es que el entorno que, hasta ahora, informaba y aportaba estructuras válidas al derecho del trabajo, se muestra inhábil para generar relatos autorizados, verdades asumibles ${ }^{60}$.

Y es que, en lo referido a la rama jurídica que aquí nos ocupa, el nuevo ciclo productivo que de modo un tanto diseminado ha podido esbozarse en las páginas anteriores, dificulta los cauces clásicos de apropiación de la riqueza generada que, durante el fordismo, se plasmaba en los cálculos tasados por la economía política: beneficios, salarios y plusvalías, computados a través de cauces regulativos de titulares de derecho definidos: empresarios y trabajadores ${ }^{6}$.

Actualmente, las producciones emanan de fuentes cada vez menos disociables, de titularidades cada vez más entreveradas, elevadas sobre sedimentaciones de cruzamientos que operan no sólo entre sujetos, sino también al interior de éstos. La producción misma, incluso, no siempre se reduce a objetos gobernables, objetos unitarios, objetos susceptibles de ser valorados unívocamente. Las porciones de trabajo muerto implicadas en los productos son cada vez menos discernibles. Así como la economía política no puede desentrañar en su marco de racionalidad elementos tasados para aumentar la riqueza de las naciones ${ }^{62}$, la crítica de la economía política no puede dilucidar qué parte del producto es legítimamente reclamable por el explotado. Las titularidades de trabajo relatadas en la modernidad se diluyen.

Las posibilidades comunicativas y tecnológicas de los tiempos están en disposición de deshabilitar todo tipo de reducción de complejidad por científica -positivista o estructuralista- que quiera suponerse: no hay economista político que apunte conceptos

${ }^{59}$ Problema clásico que, sin embargo, genera respuestas adscritas a tendencias cada vez más divergentes: «Con la invasión del post-estructuralismo, de la teoría crítica, la teoría del discurso y de la autopoiesis del mundo sociojurídico, el discurso unificado de la sociología jurídica se ha vuelto a segregar en diversas provincias culturales» (TEUBNER, G., «El derecho como sujeto epistémico», cit., pág. 6).

${ }^{60}$ En realidad, la problemática que se plantea a continuación no supone sino cierta intensificación en el uso de recursos que, a pesar del carácter esencialmente equilibrista y moderador del derecho regulativo, ya conformaban la propia esencia del mismo. No debe obviarse que la formalización de todo derecho implica ya cierta labor descriptiva transcendental, constituyente, aunque de ésta desciendan luego proposiciones vinculadas a lógicas formales: «The basic elements of capitalist society -the power of property concentrated in the hands of the few, the need for the majority to sell their labor-power to maintain themselves, the exclusion of large portions of the global population even from these circuits of exploitation, and so forth- all function as an a priori. It is even difficult to recognize this as violence because it is so normalized and its force is applied so impersonally». (HARDT y NEGRI, Commonwealth, cit., pág. 7).

${ }^{6}$ Para dar cuenta de la disolución que, desde la perspectiva de una crítica de la economía política, sucede en este modo de apropiación, véase VERCELLONE, C., «Crisis de la ley del valor y devenir renta de la ganancia», en FUMAGALLI, A., LUCARELLI, S., MARAZZI, C., NEGRI, A. y VERCELLONE, C., La gran crisis de la economía global, trad. Ezequiel Gatto, Madrid, Traficantes de sueños, 2009, págs. 63 ss.

${ }^{62}$ De hecho, la receta actual para procurar la riqueza de la nación -y del planeta como globalidad sin exteriores lo no previsible por definición, la experimentación sin anclajes de seguridad, es decir, la innovación. De ahí se derivan las literaturas que, exitosamente, describen la sociedad postmoderna en clave de riesgo, presentando el concepto casi como una suerte de categoría del entendimiento en sentido kantiano (EWALD, F., «Insurance and Risk», en G. Burchell, C. Gordon y P. Miller (ed.), The Foucault Effect. Studies in Governmentality, Chicago, University of Chicago Press, I99I, pág. I99). 
inmutables como el de trabajo y, paralelamente, no hay economista que prevea el comportamiento del mercado ${ }^{63}$.

Sin embargo, es obvio que, ante la deambulación caótica de flujos de sentido en el océano dionisiaco post, resulta innegociable la intervención de determinados procesadores: «Los decididores intentan (...) adecuar esas nubes de sociabilidad a matrices de input/output, según una lógica que implica la conmensurabilidad de los elementos y la determinabilidad del todo» ${ }^{64}$.

En cierto modo, ese procesamiento de lo inmaterial a través de la individuación jurídica sucede de modo similar a como sucedieron los cercamientos de lo material, de la tierra, en el inicio del capitalismo:

Del mismo modo que las actas de cercamiento supusieron en la Inglaterra de los siglos XVIII y XIX la sustitución de los derechos comunales por los de propiedad privada, convenimos con Moulier Boutang que, en la actualidad, podemos hablar de «las nuevas enclosures del capitalismo cognitivo ${ }^{65}$. No se trata de un proceso troquelado e indistinguible, pero, fenoménicamente, pueden equipararse rasgos y tendencias entre las actuaciones jurídicas pasadas y presentes:

Relata Moulier Boutang que el capitalismo cognitivo -entendido como el sistema económico desarrollado en torno al trabajo inmaterial como forma laboral hegemónica- «se encuentra en su fase de acumulación primitiva», la cual consiste, antes que nada, en «una acumulación de nuevos derechos» ${ }^{66}$. En esta lógica, la producción inmaterial característica del tardo-capitalismo puede ser entendida como el resultado de un proceso colectivo, como el cruzamiento complejísimo de referencias y aportaciones extrañas que, pululando por los open fields que facultan las nuevas tecnologías, convergen puntualmente en provechos o rentas delimitables. Sucede, como sucedió con la invención de la imprenta, que, ante la imposibilidad de fiscalizar implacablemente todo lo que negro sobre blanco se distribuía, se debió «aceptar la tutela del privilegio real y, por lo tanto, estatal» ${ }^{67}$. Se trata, como antes, de cercar jurídicamente los campos abiertos de donde, primariamente, surge la riqueza o donde, potencialmente, yace sin formación figurativa ${ }^{68}$.

Las enclosures acts otorgaron títulos de propiedad a campos antes no delimitados, desarrollando cierta función constituyente -casi ontológica- que reinventaba la concepción misma del paisaje. El derecho -que era el lenguaje infalible de la soberanía- llamó parcelas

${ }^{63}$ De lo que se infiere la violencia del capitalismo financiero actual (MARAZZI, C., «La violencia del capitalismo financiero», en FUMAGALLI, LUCARELLI, MARAZZI, NEGRI y VERCELLONE, La gran crisis de la economía global, cit., págs. 2I ss.).

${ }^{64}$ LYOTARD, La condición postmoderna, cit., pág. 4. Debe notarse, además, que la categoría procesadores no implica un otorgamiento en exclusiva, sino que, en los tiempos hiper-informados actuales, cada individuo -aun cambiante e irreducible a elemento fijo- constantemente actúa como procesador, como emisor de opinión/información, como actualizador de datos o discursos, como cuerpo que decide y filtra complejidades en todo momento y en todo lugar, renovando la realidad constantemente y, por tanto, renovando las consideraciones por la misma.

${ }_{65}$ MOULIER BOUTANG, Y., «Riqueza, propiedad, libertad y renta en el capitalismo cognitivo», en BLONDEAU, O., WHITEFORD, N.D., VERCELLONE, C., KYROU, A., CORSANI, A., RULLANI, E., MOULIER BOUTANG, y., LAZZARATO, M., Capitalismo cognitivo, propiedad intelectual $y$ creación colectiva, trad. Emmanuel Rodríguez, Raúl Sánchez Cedillo, Antonio García Pérez-Cejuela, Madrid, Traficantes de sueños, 2004, págs. III Ss.

${ }^{66}$ MOULIER BOUTANG, «Riqueza, propiedad, libertad y renta en el capitalismo cognitivo», cit., págs. IIIII2.

${ }_{67}$ MOULIER BOUTANG, «Riqueza, propiedad, libertad y renta en el capitalismo cognitivo», cit., pág. II3.

${ }^{68}$ Digamos, con palabras de MARAZZI («La violencia del capitalismo financiero», cit., pág. 38), que «la producción de lo común precede (...) al desarrollo capitalista, lo anticipa, lo excede, y determina sus articulaciones futuras». 
a lo que antes eran continuidades indistinguibles. El Estado -a través del derecho- fue el único sujeto con capacidad real para hacer respetar la compartimentación del territorio.

Las consecuencias socio-económicas de este proceso son conocidas: Los pequeños campesinos que labraban lo que cierta paz social les permitía -fundada en un etéreo derecho comunal- ya no pudieron hacer frente a las exigencias de terrenos independientes en los que implementar un sistema integral de explotación de la tierra. Las titularidades de los campos se concentraron en grandes propietarios que racionalizaron la labranza (rotación de cultivos, drenajes, abonos, etc), pero también la organización del trabajo, generando un gran ejército de excluidos que, a su vez, nutrieron de mano de obra barata a la industria en ciernes de las grandes ciudades.

El proceso actual de las enclosures en la sociedad del conocimiento está motivado por esa misma finalidad consustancial a todas las versiones del capitalismo: la apropiación de la riqueza generada o, siendo más exactos, la demarcación de cauces previos para la generación de riqueza que, en tanto que generada, está siendo apropiada según el lenguaje que la posibilita. El problema añadido (y esta diferencia fundamental da cuenta de la imposibilidad de un retorno mecánico a procesos pasados) es que en el capitalismo cognitivo el producto inmaterial no es fácilmente privatizable, ya que, «los bienes como el saber y la información no presentan los caracteres de exclusividad, de rivalidad, de divisibilidad, de cesibilidad, de dificultad de reproducción y de escasez que permitían mercantilizar su uso, su fruto y su reproducción» ${ }^{69}$. El capitalismo se empeña, tal vez, en un gobierno imposible $e^{70}$.

Se trata de la dificultad de encapsulamiento del producto final vinculada a la delimitación misma del trabajo previo a la trascendencia mercantil. Si en la época fordista el trabajo debía canalizarse hacia una puesta en común para la obtención de un producto final menos costoso (puesta en común organizada en la fábrica y regulada por la legislación laboral moderna) era, precisamente, porque el trabajo quedaba innegociablemente vinculado a la potencia individual de los cuerpos, de tal modo que el empresario, el trabajador y el jurista debían proponer una socialización del trabajo originariamente individual. La delimitación del proceso en un sistema estanco facultaba la negociación por el salario entre los sujetos intervinientes en el producto final, conforme a determinados cálculos referidos a un universo cerrado.

En la actualidad sucede, como anticipábamos, que esos sistemas estancos de producción no existen (o están en declive), de tal modo que la manera de ordenar el trabajo absolutamente abierto, cruzado y multi-referencial pasa, precisamente, por su individuación jurídica ${ }^{7 \mathrm{I}}$.

Se trata, por tanto, de una función inversa: La individuación jurídica del trabajo implica definir titularidades del trabajo que no se asumen definidas por una ciencia externa $\mathrm{y}$, por consiguiente, reducir la complejidad inabordable del producto derivado, haciéndolo apto para ser cercado por los grandes capitales. La individuación jurídica del trabajo es una mediación hacia la privatización final de una mercancía extraída de un campo común y

\footnotetext{
69 MOULIER BOUTANG, «Riqueza, propiedad, libertad y renta en el capitalismo cognitivo», cit., pág II7.

$7^{\circ}$ RODRÍGUEZ, E., El gobierno imposible. Trabajo $y$ fronteras en las metrópolis de la abundancia, Madrid, Traficantes de sueños, 2003 .

${ }^{71}$ Tomamos el concepto individuación en el sentido de VIRNO (Cuando el verbo se hace carne, cit., págs. 80 ss.), advirtiendo que, si bien la capacidad del individuo para comunicar, para trabajar inmaterialmente, aparenta un modo de socialización, de comunión con el entorno, inversamente, en el plano jurídico, sucede un modo de singularización, de significación diferenciada del agente que, nutriéndose de una totalidad comunicativa (de una sociedad previa), se diferencia, ofrece nuevas posibilidades para el ciclo productivo y puede ser captado por el capital que financia (o no), en tanto que personalidad jurídica deslindada del entorno.
} 
reticular. Es el modo de atrapar externalidades positivas, fomentadas en la medida y forma en que pueden ser apropiadas.

\section{Constitución del derecho laboral postregulativo: la función performativa ${ }^{2}$}

Durante la modernidad, el relato que legitimaba el desarrollo jurídico era el de la norma constituyente ${ }^{73}$, generadora de tentáculos pretendidamente legatarios de las intenciones originarias, como proceso determinado, el único posible. Las primeras excepciones sobrevinieron, como apuntábamos, en el ámbito del derecho laboral que, en contacto con la complejidad extrajurídica, desarrolló legislaciones informadas desde exteriores especializados, desde metarrelatos capaces de narrar el mundo sobre la figuración propuesta por la épica dialéctica empresarios/trabajadores.

Sucede, sin embargo, en las condiciones postmodernas advertidas por Lyotard, que «el propio relato (que legitima la legislación del pueblo) aparece ya como insuficiente para dar una versión completa» ${ }^{74}$, de modo que se hacen necesarios microrrelatos variados, interactivos y ajustados a realidades diversas, efímeras, coyunturales, fluidas; realidades imposibles de ser procesadas mediante una habilitación competencial como la aportada por la economía política, y mucho menos aún por normas constituүentes primigenias; La positividad iuslaboral desarrollada a partir de aquellos relatos ya sólo puede contradecirse a sí misma $^{75}$. Es así como el derecho laboral se reproduce en narrativas variopintas, alternando el rigor que pretendió como ciencia con la fábula de relatos míticos; esos que, en opinión de Lyotard, no necesitan ser autorizados más allá de sí mismos y de su aceptación ${ }^{76}$.

El nuevo derecho laboral, por tanto, se proyecta como paradigma de adaptación jurídica a estas derivas que ponen en crisis las ciencias informativas del campo jurídico. Aun antes de que el derecho regulativo se haya implantado en el resto de ámbitos jurídicos, el derecho referido al trabajo ya muestra importantes grietas en un método que se suponía triunfante, basado en renegar de la estanqueidad del derecho e informarse a partir de expertos externos ${ }^{77}$. Porque si la integridad del derecho laboral -en tanto que relato indemne- estaba anclada al marco de racionalidad que proponía la economía política -aun como dispositivo que marca su primera crisis-, lo novedoso es que el mismo marco de racionalidad de la economía política se muestra ahora incapaz de generar verdades científicas sobre las que pueda construirse el derecho del trabajo.

En este escenario, por tanto, el derecho laboral mantiene su marco nominal para, en la práctica, desarrollar una serie de técnicas que ya se han mostrado eficaces en otros ámbitos menos hipotecados a tradiciones formalistas o regulativas, ámbitos que se abren como realidades novedosas sobre las que nunca ha regido un derecho regulativo en sentido estricto $^{78}$. El derecho laboral propone, así, un modo de regular basado no ya en la

\footnotetext{
${ }^{72}$ En el sentido de VIRNO (Cuando el verbo se hace carne, cit., págs. 6I ss.).

${ }_{73}$ «Norma fundante básica como presupuesto lógico-trascendental» (KELSEN, H., Teoría pura del derecho, trad. Roberto Vernengo, México, Porrúa, 1997, pág. 208)

${ }^{74}$ LYOTARD, La condición postmoderna, cit., pág. 27.

${ }^{75}$ En esta sintomatología se encauza la literatura que advierte de la crisis del derecho del trabajo. Véase, por ejemplo: CARRETERO MIRAMAR, J.L., «La imparable crisis del derecho del trabajo», Nómadas: revista crítica de ciencias sociales $y$ jurídicas, $\mathrm{n}^{\circ}$ I9, 2008 , págs. 415-420.

${ }^{76}$ LYOTARD, La condición postmoderna, cit., pág. 20.

${ }^{77}$ Se trata de «la incorporación de otros 'saberes' y otros 'expertos' en las dinámicas regulativas» (CALVO GARCÍA, «Transformaciones del derecho», cit., pág. 7I).

${ }^{78}$ Nos referimos, sobre todo, al ámbito de la informática y las nuevas tecnologías, donde rige un modo de lex informatica que no prescribe conductas sobre sujetos, sino que restringe las posibilidades tecnológicas que gestionan la comunicación misma (Regulation by Technology). En cierto modo se adecua constantemente el campo comunicativo cambiante a una higiene igualmente variable. Véase, por ejemplo, REIDENBERG, J., «Lex
} 
emanación soberana de derechos y obligaciones que habrán de recaer sobre sujetos apriorísticos definidos por otros expertos (o por una norma constituyente de seres humanos iguales entre sí), sino que propone implementar elementos necesarios para que cualquier forma de producción de riqueza (prevista o no) siga produciendo riqueza en la medida en que ésta podrá ser mercantilizada. Se trata, por tanto, de disponer garantías mínimas para que lo que se ha mostrado productivo en cualquier formato experimental, no deje de serlo, y, a su vez, sea institucionalizado ${ }^{79}$. Se trata de un modo de regulación por la comunicación.

Y para mantener la formalidad regulativa, supeditar la actividad a un marco formal de razonabilidad y seguir proyectando la legitimidad moderna, el derecho laboral pone en práctica una producción lingüística sin precedentes. La tendencia es la disgregación en formas contractuales cada vez más adaptadas a situaciones concretas y eventuales o, en su vertiente más traumática, la proyección del contrato mercantil como única relación posible entre trabajadores autónomos ${ }^{80}$ (siempre dispuestos al evento aislado), quedando el derecho laboral en mero habilitador de la posibilidad y, si acaso, en regulador de la higiene del campo, es decir, como prevención de riesgos laborales. En ese tránsito del derecho laboral al derecho mercantil, la inventiva lingüística juega un papel de transición crucial, ya que debe desarmarse el entramado iuslaboral anterior -deudor de ciencias inadaptas- conforme a nuevas constituciones aptas ${ }^{8 \mathrm{I}}$.

Esta dinámica de constituciones aptas vinculadas a estratégicos interruptores de

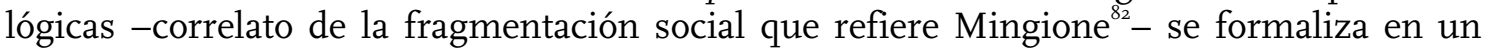
gran volumen de producción jurídica que en España se hace visible, sobre todo, a través de las políticas de empleo (vinculadas a los servicios públicos de empleo autonómicos). Sin embargo, la exposición más franca de esta lógica como punta de lanza de un nuevo modo de hacer política laboral es la que hace la Ley 20/2007, de iI de junio, del Estatuto del

Informatica: The Formulation of Information Policy. Rules Through Technology», Texas Law Review, $\mathrm{n}^{\circ}$ 3, vol. 76, I998, págs. 553-584; LESSIG, L., El código y otras leyes del ciberespacio, Madrid, Taurus, 2002; Code 2.0, New York, Basic Books, 2006; DOMMERING, E.J. y ASSCHER, L.F. (eds.), Coding regulation. Essays on the normative role of Information Technology, The Hague, Asser Press, 2006.

${ }^{79}$ Véase, para situar el fenómeno de los hechos institucionalizados en una teoría global, SEARLE, J.R., La construcción de la realidad social, cit. $\mathrm{O}$, para una interpretación más localizada, entiéndase la función del derecho como texto en cierto sentido que le imprime CLAVERO (Happy Constitution, cit., pág. I52).

${ }^{80}$ Proyectamos una distopía: una sociedad de trabajadores autónomos que se relacionan con financiadores y clientes mediante el derecho mercantil. Esta distopía, invertida, apunta a una forma consumada (aunque ficticia -véase, para dar cuenta de la ficción, PÉREZ GONZÁLEZ, Trabajo autónomo, individualización y posibilidades colectivas, en BERNUZ, M.J y SUSÍN, R. (coord.), Seguridad, excepción y nuevas realidades jurídicas, Granada, Comares, 20I0, pág I97) de la utopía proyectada originariamente por los arquitectos del Estado moderno: el autónomo como sujeto y ciudadano libre e igual, inalterado ante las rupturas proyectadas por ciencias externas. La narración de Lyotard puede aportar cierta esperanza al respecto: «De esta descomposición de los grandes Relatos (...) se sigue eso que algunos analizan como la disolución del lazo social y el paso de las colectividades sociales al estado de una masa compuesta de átomos individuales lanzados a un absurdo movimiento browniano». Sin embargo, según el filósofo francés, en este cambio de paradigma se articulan nuevas posibilidades, ya que «El sí mismo es poco, pero no está aislado, está atrapado en un cañamazo de relaciones más complejas y más móviles que nunca. (...) Nunca está, ni siquiera el más desfavorecido, desprovisto de poder sobre esos mensajes que le atraviesan al situarlo, sea en la posición de destinador, o de destinatario, o de referente» (LYOTARD, La condición postmoderna, cit. pág. I5). Posibilidades, por otro lado, ya adelantadas por Mijail Bajtin (junto o a través de su discípulo: VOLOSHINOV, V., El marxismo y la filosofía del lenguaje, trad. Tatiana Bubnova, Madrid, Alianza, I992) y que dieron cuenta de la dicotomía posible entre la conformación de un antagonismo organizado institucionalmente y un antagonismo reticular, sin jerarquías, depositado sobre la potencia misma del lenguaje.

${ }^{81}$ Usamos el término en un sentido aproximado al indicado por ESKRIDGE, N. y FEREJOHN, J. para el concepto super-statute, si bien no referimos tanto categorías diferenciadas en la producción normativa como tendencias globales del derecho: «A super-statute is a law or series of laws that seeks to establish a new normative or institutional framework for state policy» (Super-statutes, Duke Law Journal, 200I, vol. 50, pág. I2I6).

${ }^{82}$ MINGIONE, E., Las sociedades fragmentadas: una sociología de la vida económica más allá del paradigma del mercado, Madrid, $\mathrm{M}^{\circ}$ Trabajo y S.S., I994. 
trabajo autónomo; «una Ley que en su propio preámbulo se reconoce como el 'primer ejemplo de regulación sistemática y unitaria del trabajo autónomo en la Unión Europea, lo que sin duda constituye un hito en nuestro ordenamiento jurídico'. Se trata, corroboramos, de una regulación sistemática y unitaria, pero aplicada a la acreditación de una figura (la del trabajador autónomo) que se infiltra en el panorama jurídico para luego revelarse como el ideal desnormalizador -desistematizador- de la idea social anterior. Se fomenta al autónomo, por tanto, como paradigma antitético de la forma jurídica asalariada clásica» ${ }^{83}$, como desintegrador de las verdades científicas que proponía la economía política ${ }^{84}$, como relato circunstancial construido sobre la mera experiencia ${ }^{85}$.

Más literaria aún resulta -incluida en la misma Ley- la aventura del trabajador autónomo económicamente dependiente ${ }^{86}$, Porque la literatura potencia las contradicciones que, otrora ilógicas, abren ahora posibilidades fantásticas hacia la innovación y reinvención de mundos. Porque la creación de riqueza pasa, en esta nueva lógica, por actualizar jurídicamente las experiencias que se han mostrado eficaces, más allá de su inserción lógico-formal en el marco de racionalidad propuesto por la ciencia que informaba, históricamente, al derecho.

Es así, por tanto, como el derecho laboral se resuelve en juego de lenguaje cada vez menos anclado a verdades externas y, menos aún, a grandes principios constitucionales. El derecho del trabajo se muestra cada vez más enmarañado, persiguiendo realidades burlescas, cada vez más desgarrado y cada vez más cerca de convertirse en una constelación de fragmentos legitimadores de eventualidades, como desinvirtiendo el proceso codificador.

Pero esta tendencia no es unívoca, sino que se desarrolla en modos igualmente cruzados y lógicas solapadas ${ }^{87}$. Mientras una parte del derecho laboral se afana por regular (aun desregulando socialmente) según lo dispuesto en el marco de racionalidad dicotómico moderno (explotadores/explotados), dirimiendo acerca de los tipos de contratos y relajando a golpe de reforma laboral las características inadaptadas a los tiempos postfordistas ${ }^{88}$, otra parte del derecho laboral, la más imaginativa, propone asumir y fomentar discriminadamente las concepciones que, a partir de las incontables experiencias, resultan más apropiadas: las prácticas, las becas, las cooperativas, las economías sociales, las

\footnotetext{
${ }^{83}$ PÉREZ GONZÁLEZ, S., «Trabajo autónomo, individualización y posibilidades colectivas», cit., pág. I85.

${ }^{84}$ Recordemos que el propio Marx (MARX, K., El capital: crítica de la economía política, trad. Cristián Fazio, Moscú, Progreso, I990, vol. I, pág 563), en su crítica de la economía política, -si proyectamos al futuro su definición de proletario- deja fuera de la categoría de explotados al trabajador autónomo e incluso a todo tipo de trabajadores dedicados a la comercialización y distribución -en contraste con el trabajo productivo estricto.
}

${ }^{85}$ Cabe señalar que hace apenas unas décadas, el autónomo, así como la cooperativa o la economía social, eran reivindicados como modos cuasi-subversivos de resistencia al patronato fabril.

${ }^{86}$ «'La intención del legislador es eliminar esas zonas fronterizas grises’, dice la propia Ley, de modo que la solución política parece apuntar a la creación de categorías que, de una manera u otra, circunvalen la efectividad del derecho más evolucionado -de la Ley en la que cristalizaron buena parte de los intereses colectivos sociales en décadas anteriores (el Estatuto de los trabajadores)-. Se trata, por tanto, de actualizar constantemente el testimonio jurídico de la pluralidad antes que someter la realidad a cualquier proyecto reductor de complejidad, tal vez porque eso supondría -a tenor de la nueva epistemología hegemónica- socavar la íntima autonomía del individuo» (PÉREZ GONZÁLEZ, S., «Trabajo autónomo, individualización y posibilidades colectivas», cit., pág. I87).

${ }^{87}$ «La simultaneidad en la dependencia e independencia respecto de los otros discursos sociales es la razón por la cual el Derecho moderno está permanentemente oscilando entre posiciones de autonomía y heteronomía cognitiva» (TEUBNER, «El derecho como sujeto epistémico», cit., pág. I2).

${ }^{88}$ Aunque, como decimos, un marco de racionalidad también cruzado internamente, introduciendo tecnologías que reconciben, por ejemplo, lo que debe considerarse indefinido: Véase, en este sentido, PALOMEQUE LÓPEZ, M.C., «Contratos de trabajo indefinidos temporales (la duración del contrato como observatorio de las transformaciones económicas del ordenamiento laboral)», Relaciones laborales: Revista crítica de teoría y práctica, $\mathrm{n}^{\circ} \mathrm{I} 7,2009$, págs. $\mathrm{I7}-38$. 
autogestiones productivas, los autoempleos, los autónomos económicamente dependientes, etc $^{89}$.

El derecho laboral, como vemos, asume la técnica compositiva más eficaz para estos tiempos y espacios hipercomunicados: atrás quedan pirámides de ordenación vertical o asunciones de estructuras estáticas producidas en un metarrelato exterior. La tendencia iuslaboral procede, horizontalmente, a calibrar las formas posibles de ordenación experimentadas y, puntualmente, elevarlas a ley o fomentarlas mediante subvenciones, es decir, procurar la concurrencia de experiencias productivas diversas en esas formas determinadas y efímeras. Se trata, teniendo en cuenta la esencia lingüística de lo jurídico, no tanto del giro lingüístico del derecho laboral como de la vuelta de tuerca lingüística del derecho laboral, que es el modo en el que el derecho se asimila a la lógica del performativo absoluto apuntado por Virno ${ }^{9 \circ}$ : La capacidad para conservar la figuración del trabajo (esto que se dice) radica en la facultad de locución (el hecho que se habla), ya que si el derecho menta nuevas formas del trabajo, éstas ya no pueden ser contradichas por la economía política ${ }^{9 \mathrm{I}}$.

Y es que la profesión jurídica, en la deriva inmaterial de todos los trabajos ${ }^{92}$, reinventa su valor en la medida en que, en último término, produce riqueza mediante el lenguaje; el éxito del derecho laboral en una época post radica en mostrarse legítimo en tanto que puro lenguaje ${ }^{93}$. El trabajo, así, sólo existe diferenciado del resto de actividades en tanto que el derecho lo nombra. El derecho laboral es, básicamente, el arte hacedora de nombres para una economía cruzada, cooperativa e incodificable ${ }^{94}$.

Ya no es eficaz un derecho que trata de regular los cauces productivos y sobre cuyo diámetro, longitud o grosor pueda negociarse colectivamente amparado en la legitimidad de ser un sujeto presupuesto, sino que, en el escenario post, el derecho laboral pretende mantener las canalizaciones de apropiación de riqueza en un mundo de Commonwealth (HARDT Y NEGRI, cit.), un mundo de trabazón, cooperativismo y redes sociales en el que ya no pueden diferenciarse méritos sino mediante ficciones jurídicas que desbordan todo marco racional. Lo que ahora trasciende del derecho laboral es el preámbulo, la literatura libre, la reinvención del sujeto (autónomo, cooperativista, becario, comisionado...) y la creación de miles de nuevas relaciones cambiantes, adaptación siempre insuficiente al

\footnotetext{
${ }^{89}$ «En vez de un código binario y estable [trabajador-no trabajador], lo que aparecen son miles de figuras y relatos asimétricos y con identidades inestables (aunque muchas veces grotescas o sacrificadas, cínicas, inestables, tradicionales, etc.)»(ALONSO, La crisis de la ciudadanía laboral, cit., pág. 254). Especialmente paradigmático resulta, debido a su relación directa con la producción cognitiva, la multitud de posibilidades contractuales que ofrece la carrera académica universitaria, en la que la canalización de las experiencias productivas se formaliza en relatos híbridos y cruzados (Ley Orgánica 6/200I, de 2I de diciembre, de Universidades, (BOE núm. 307 de 24/I2/200I ), Título IX, Capítulo I, Secciones I y II).

${ }^{\circ}$ VIRNO, P., Cuando el verbo se hace carne, cit., págs. 6I ss.

${ }^{91}$ «El realismo epistemológico se transforma en un nuevo constructivismo epistemológico (y), a tenor de la epistemología social constructivista, las percepciones del Derecho respecto de la realidad no se corresponden con algún tipo de realidad social que está 'ahí fuera'. Por el contrario, es el Derecho el que, como sujeto epistémico autónomo, construye su propia realidad social (...) Es el Derecho el que, como proceso comunicativo, crea actores humanos como artefactos semánticos a través de sus operaciones jurídicas» (TEUBNER, «El derecho como sujeto epistémico», cit., págs. II-I2).

${ }^{22}$ Véase, para dar cuenta de las complejidades que conforman el operar ideológico de los juristas, JOHNSEN, J.T., «Professional and common Legal Understanding», en FERRARI, V., Laws and Rights, Milano, Giuffrè, I99I.

93 «La legitimación no puede venir de otra parte que de su práctica lingüística y de su interacción comunicacional» (LYOTARD, La condición postmoderna, cit., pág. 34).

${ }^{94}$ Si el trabajo -desde cierta fenomenología heideggeriana- era un modo de ser en su finitud, sucede que, desprovisto ahora de su apariencia fenoménica, el derecho se erige como intuición intelectual capaz de discernir su esencia a partir de una existencia lisa, indescifrable por nuestros sentidos. El trabajo parece tomar la forma ideal del noúmeno platónico y, si acaso, nuestras actividades demasiado humanas encajan en ese valor incognoscible en la medida en que la ley lo instituye, como palabra de demiurgo. Se trata de un modo de apriorismo jurídico actualizado a alta frecuencia.
} 
devenir inasible que es la economía social. Ya no hay ciencia u horizonte científico que informe. Ya no hay saltos cualitativos que compongan realidades cerradas, sino adaptación al medio sin anclajes formales.

Se trata, por tanto, de relatos adaptados al momento, se trata de habilitaciones que sólo quedan unidas a otras habilitaciones anteriores o a verdades externas mediante lógicas cada vez menos probables y más arbitrarias, sin pautas para la elaboración de estructuras previsoras. Se trata de constituciones que, ex nihilo, proponen nuevas compartimentaciones de la realidad y, por tanto, campos abiertos para regulaciones derivadas, aunque de permanencia dudosa (su adaptación a los flujos de sentido globales puede caducar en cualquier momento). Podemos referirnos, así, a una cierta atomización constitucional laboral.

De este modo, el derecho posibilita que el conocimiento desfigurado, el saber gaseoso que pulula, se condense puntualmente en servicios o mercancías legalmente finitas, es decir, momentos de comercio. Esos momentos de comercio-solidificaciones del general intellect- son aprovechados por la instancia del capital que obtiene plusvalía de un saber siempre capaz de revalorizarse tras su venta. El capital es ahora refinamiento de saberes, objetivación de subjetividades hiperdinámicas ${ }^{95}$. El capital es resituación, revalorización de las vidas del pequeño cognitariado, siempre de encargo en encargo.

\section{Conclusiones}

El derecho laboral, en este panorama descrito, ya no es un lenguaje referido a lenguajes. Ya no es un índice ordenador del lenguaje creado por la economía política, sino que el derecho laboral desarrolla la potencia máxima del lenguaje mismo, institucionalizador de nociones que no son herencia pacífica de otras ciencias. El derecho parece, entonces, cubrir el vacío que la crisis de la modernidad propone. El derecho, en el ámbito descrito casi como una evolución reflexiva del Rule of Law originario-, asume la función de ciencia en un mundo post en el que el resto de ciencias han perdido su infalibilidad. Lo único infalible es, casi como una religión ${ }^{96}$, lo que se auto-refiere infalible: el derecho (laboral, en lo que a nuestro estudio compete).

La experiencia del derecho del trabajo apunta, en el modo relatado, a un intento de repliegue del derecho sobre sí mismo. Sugiere, en definitiva, un nuevo estadio de desarrollo de las formas jurídicas que, despuntando entre el derecho regulativo propio de otros ámbitos, marca un igualmente renovado campo de batalla teórico ${ }^{97}$.

Las dinámicas económicas y políticas son cada vez menos discernibles en sus circuitos autónomos, de modo que cada individuo parece actuar en un espacio liso de entera libertad, paulatinamente encauzado por procesadores diversos hacia formas subyugantes. Pero las formas subyugantes, las formas de encapsulamiento de las experiencias inenarrables, para ser eficaces, requieren, igualmente, maleabilidad y flexibilidad, capacidad

\footnotetext{
${ }_{95}$ Porque «el capital no es una cosa, sino que es una relación social, una relación antagónica» (HARDT, M. y NEGRI, A., Imperio, trad. Alcira Bixio, Barcelona, Paidós , 2002, pág. 382).

${ }^{96}$ VIRNO, Cuando el verbo se hace carne, cit., pág. 88. Por tanto, si bien el derecho regulativo generó «aperturas de dogmas» en la integridad formal del derecho (CALVO GARCÍA, «Transformaciones del derecho», cit., pág. 76), puede proyectarse ahora cierto retorno al dogma, a las formas religiosas en el derecho postregulativo.

${ }^{77}$ Convenimos con CALVO GARCÍA («Transformaciones del derecho», cit., pág. 73) que el derecho regulativo (...) representa el tipo de derecho predominante en los Estados contemporáneos. Sin embargo, del mismo modo que Nonet y Selznick referían el «Estado regulativo del bienestar» como marco de «un nuevo estado evolutivo en la cadena jurídica, (como) nuevo paradigma en la evolución legal» (CALVO GARCÍA, «Transformaciones del derecho», cit., pág. 66 y 67), apuntamos que las dinámicas descritas hasta aquí refieren, igualmente, síntomas de la superación de aquellos modos regulativos.
} 
de acto-reflejo: la misma ductilidad que la literatura, históricamente, ha puesto en práctica para no agotarse nunca, para descubrir mundos, perspectivas, sensaciones...

En este rumbo -o deriva sin destino fijo- parece encaminado el derecho referido al trabajo. Ya no sirven lógicas deducidas de tesis primigenias, procesos prefabricados en los que someter a los individuos trabajadores, o un derecho regulativo aplicado a un campo delimitado, continente de elementos tasados, fijos y estáticos.

Porque el derecho se transfigura, en esta lógica, en un modo selector de experiencias productivas adecuadas; una selección que, sin embargo, no permanece más allá de una caducidad cada vez más inminente.

La interpretación publicitada como positiva es que estos nuevos modos jurídicos permiten la riqueza de las naciones: crecimiento económico y bolsas alcistas. Permiten la abundancia que, sin embargo, cada vez se vincula menos a aquella subsistencia clásica ${ }^{98}$. De hecho, en representaciones cada vez más grotescas, la lucha por la abundancia y por la subsistencia cohabitan sin pudor.

La interpretación negativa (menos publicitada) es que, enmarañados en un derecho postregulativo, la posibilidad de interacción con estas derivas resulta extraordinariamente compleja. Tan compleja como actuar en minúsculas continuidades de lógica formal -o aun de racionalidad sustantiva- que, en cualquier momento, pueden ser interrumpidas. La hegemonía, si se produjera, de este tipo de derecho, contraría la misma esencia de los sistemas políticos que lo amparan y se proponen como marco de racionalidad global.

De lo visto se deduce que estas conclusiones se postulan no tanto como terminaciones, sino como presupuestos que sospechan modos distintos en las dinámicas jurídicas contemporáneas. Desde esta posibilidad cabría sondear, paralelamente, nuevas maneras de interacción social. Las propuestas, por tanto, no podrán componer un corpus cerrado de disposiciones ya que, como las inescrutables veredas del derecho, deberán estar continuamente abiertas a su propia renovación. Porque ésta es la única sugerencia posible: la interacción con este nuevo modo de hacer derecho deberá ser tan imaginativa como, hasta el momento, se muestran las derivas iniciadas.

\section{Bibliografía citada}

ALONSO, L.E., La crisis de la ciudadanía laboral, Barcelona, Anthropos, 2007.

ALTHUSSER, L., «Dos o tres palabras (brutales) sobre Marx y Lenin», L’Espresso, año XXIV, nº 4, I978.

ARENDT, H., La condición humana, Barcelona, Paidós, I998.

BATAILLE, G., La parte maldita (precedida de la noción de gasto), trad. Francisco Muñoz de Escalona, Barcelona, Icaria, I987.

BAUDRILLARD, J., La sociedad de consumo: sus mitos, sus estructuras, trad. Alcira Bixio, Madrid, Siglo XXI, 2009.

BECKER, H.S., Outsiders: hacia una sociología de la desviación, trad. Jaime Arrambide, Buenos Aires, Siglo XXI, 2009.

BERARDI, F., La fábrica de la infelicidad. Nuevas formas de trabajo y movimiento global, Traficantes de Sueños, Madrid, 2003.

$9^{8}$ «Hay algo más en la epistemología social que el interés de los actores sociales responsables de la manipulación del conocimiento» (TEUBNER, «El derecho como sujeto epistémico», cit., pág. I3), a lo que añadimos que, más allá de manejos atribuibles a sujetos e intereses localizables, esta tendencia jurídica se muestra, en términos abstractos, más apta. ¿Debemos deducir, por tanto, que se trata de una tendencia innegociable? 
BLONDEAU, O., WHITEFORD, N.D., VERCELLONE, C., KYROU, A., CORSANI, A., RULLANI, E., MOULIER BOUTANG, y., LAZZARATO, M., Capitalismo cognitivo, propiedad intelectual y creación colectiva, trad. Emmanuel Rodríguez López, Beñat Baltza, Antonio García Pérez-Cejuela, Madrid, Traficantes de sueños, 2004 .

CALLINICOS, A., Contra el postmodernismo: una crítica marxista, trad. Magdalena Holguín, Bogotá, Ancora I994.

CALVO GARCÍA, M. «Transformaciones del derecho. Democracia y principio de legalidad en el Estado regulativo», CALVO GONZÁLEZ, J. y MONEREO ATIENZA, C., Filosofía Jurídica y siglo XXI. Ocho panoramas temáticos, Universidad de Málaga, Málaga, 2005, págs. 57-80.

CARRETERO MIRAMAR, J.L., «La imparable crisis del derecho del trabajo», Nómadas: revista crítica de ciencias sociales $y$ jurídicas, $\mathrm{n}^{\circ} \mathrm{I} 9$, 2008, págs. 415-420.

CORSANI, A., «Hacia una renovación de la economía política. Antiguas categorías e innovación tecnológica», en BLONDEAU, O., WHITEFORD, N.D., VERCELlONE, C., KYROU, A., CORSANI, A., RULLANI, E., MOULIER BOUTANG, y., LAZZARATO, M., Capitalismo cognitivo, propiedad intelectual y creación colectiva, trad. Emmanuel Rodríguez López, Beñat Baltza, Antonio García Pérez-Cejuela, Madrid, Traficantes de sueños, 2004, págs. 89-98.

CLAVERO, B., Happy Constitution: cultura y lengua constitucionales, Madrid, Trotta, I997.

DAVID RICARDO, Principios de Economía Política Y Tributación, trad. E. Hazera, Barcelona, Orbis, I985.

DOMMERING, E.J. y ASSCHER, L.F. (eds.), Coding regulation. Essays on the normative role of Information Technology, The Hague, Asser Press, 2006.

ENGELS, F., Introducción a la dialéctica de la naturaleza; El papel del trabajo en la transformación del mono en hombre, Madrid, Ayuso, I974.

ESKRIDGE, N. y FEREJOHN, J., «Super-statutes», Duke Law Journal, 200I, vol. 50, págs. I2I5-I276.

EWALD, F., «Insurance and Risk», en G. Burchell, C. Gordon y P. Miller (ed.), The Foucault Effect. Studies in Governmentality, Chicago, University of Chicago Press, I99I.

FREUD, S., El malestar en la cultura y otros ensayos, Madrid, Alianza, I980.

FUKUYAMA, F., The end of History and the Last Man, New York, The Free Press, 1992.

FUMAGALLI, A., Bioeconomía y capitalismo cognitivo. Hacia un nuevo paradigma de acumulación, Traficantes de Sueños, Madrid, 2010.

FUMAGALLI, A., LUCARELLI, S., MARAZZI, C., NEGRI, A. y VERCELLONE, C., La gran crisis de la economía global. Mercados financieros, luchas sociales y nuevos escenarios políticos, trad. Ezequiel Gatto, Madrid, Traficantes de sueños, 2009.

GORZ, A., Metamorfosis del trabajo, trad. M. Carmen Ruiz, Madrid, Sistema, I995.

HARDT, M. y NEGRI, A., Imperio, trad. Alcira Bixio, Barcelona, Paidós , 2002.

HARDT y NEGRI, A., Multitud. Guerra y democracia en la era del Imperio, trad. Juan Antonio Bravo, Barcelona, Debate, 2004 .

HARDT, M. Y NEGRI, A., Commonwealth, Cambridge, Harvard University Press, 2009.

JOHNSEN, J.T., «Professional and common Legal Understanding», en FERRARI, V., Laws and Rights, Milano, Giuffrè, I99I.

KELSEN, H., Teoría pura del derecho, trad. Roberto Vernengo, México, Porrúa, I997.

LASTRA LASTRA, «El trabajo en la Historia», Anuario Mexicano de Historia del Derecho, nºII-I2, 2000, págs. I95-224.

LAZZARATO, Lavoro immateriale. Forme di vita e produzione di soggettività, Verona, Ombre Corte, I997.

LAZZARATO, M., Por una política menor. Acontecimiento y política en las sociedades de control, trad. Pablo Rodríguez, Madrid, Traficantes de sueños, 2006.

LESSIG, L., El código y otras leyes del ciberespacio, Madrid, Taurus, 2002.

LESSIG, L., Code 2.0, New York, Basic Books, 2006.

LUHMANN, N., El derecho de la sociedad, México D.F., Univ. Iberoamericana, 2002.

LUKACS, G., Historia y consciencia de clase, trad. Manuel Sacristán, Madrid, Sarpe, I984, 2 vol.

LYOTARD, J.F., La condición postmoderna, trad. Mariano Antolín, Buenos Aires, Cátedra, I99I. 
MARAZZI, C., El sitio de los calcetines: El giro lingüístico de la economía y sus efectos sobre la política, trad. Marta Malo de Molina Bodelón, Madrid, Akal, 2003.

MARAZZI, C., «La violencia del capitalismo financiero», en FUMAGALLI, LUCARELLI, MARAZZI, NEGRI y VERCELLONE, La gran crisis de la economía global. Mercados financieros, luchas sociales y nuevos escenarios políticos, trad. Ezequiel Gatto, Madrid, Traficantes de sueños, 2009.

MARSHALL, T.H., Ciudadanía y clase social, trad. Pepa Linares, Madrid, Alianza, I998.

MARX, K., El capital: crítica de la economía política, trad. Cristián Fazio, Moscú, Progreso, I990.

MINGIONE, E., Las sociedades fragmentadas: una sociología de la vida económica más allá del paradigma del mercado, Madrid, $\mathrm{M}^{\circ}$ Trabajo y S.S., I994.

MOULIER BOUTANG, Y., «Riqueza, propiedad, libertad y renta en el capitalismo cognitivo», en BLONDEAU, O., WHITEFORD, N.D., VERCELlONE, C., KYROU, A., CORSANI, A., RULlANI, E., MOUlIER BOUTANG, y., LAZZARATO, M., Capitalismo cognitivo, propiedad intelectual y creación colectiva, trad. Emmanuel Rodríguez, Raúl Sánchez Cedillo, Antonio García Pérez-Cejuela, Madrid, Traficantes de sueños, 2004, págs. I07-I28.

NAPOLEONI, C., Fisiocracia, Smith, Ricardo, Marx, Barcelona, Oikos-Tau, I974.

PALOMEQUE LÓPEZ, M.C., «Contratos de trabajo indefinidos temporales (la duración del contrato como observatorio de las transformaciones económicas del ordenamiento laboral)», Relaciones laborales: Revista crítica de teoría y práctica, $\mathrm{n}^{\circ} \mathrm{I7}, 2009$, págs. $17-38$.

PÉREZ GONZÁLEZ, S., «Trabajo autónomo, individualización y posibilidades colectivas», en BERNUZ, M.J y SUSÍN, R. (coord.), Seguridad, excepción y nuevas realidades jurídicas, Granada, Comares, 2010.

REIDENBERG, J., «Lex Informatica: The Formulation of Information Policy. Rules Through Technology», Texas Law Review, $\mathrm{n}^{\circ}$ 3, vol. 76, I998, págs. 553-584.

RICARDO, D., Principios de Economía Política y Tributación, trad. E. Hazera, Barcelona, Orbis, I985.

RODRÍGUEZ, E., El gobierno imposible. Trabajo y fronteras en las metrópolis de la abundancia, Madrid, Traficantes de sueños, 2003.

SANCHÍS GÓMEZ, E. «Concepciones del trabajo: de las ambigüedades medievales a las paradojas actuales», Cuadernos de Relaciones Laborales, v.22, nº, págs. 37-65.

SANTOS ORTEGA, A. Y POVEDA ROSA, M. Trabajo, empleo y cambio social, Valencia, Tirant lo blanch, 2002.

SCHUMPETER, J.A., Capitalismo, socialismo y democracia, Barcelona, Folio, I984.

SEARLE, J.R., La construcción de la realidad social, trad. Antoni Domènech, Barcelona, Paidós, 2004.

SMITH, A., Una investigación sobre la naturaleza y causas de la riqueza de las naciones, trad. Carlos Rdguez. Braun, Madrid, Tecnos, 2009.

TEUBNER, G., «El derecho como sujeto epistémico», Doxa: cuadernos de filosofía del derecho, n 25, I989, págs. 4-88.

TEUBNER, G., El derecho como sistema autopoiético de la sociedad global, Bogotá, UEC, 2005.

VERCELLONE, C., «Crisis de la ley del valor y devenir renta de la ganancia», en FUMAGALLI, A., LUCARELLI, S., MARAZZI, C., NEGRI, A. y VERCELLONE, C., La gran crisis de la economía global, trad. Ezequiel Gatto, Madrid, Traficantes de sueños, 2009, págs. 63-98.

VIRNO, P., Cuando el verbo se hace carne: Lenguaje y naturaleza humana, trad. Eduardo Sadier, Madrid, Traficantes de sueños, 2005.

VOLOSHINOV, V., El marxismo y la filosofía del lenguaje, trad. Tatiana Bubnova, Madrid, Alianza, I992.

YARZA, I., «Sobre la praxis aristotélica», Anuario Filosófico, nº I9, I986, p. I35-I53. 